\title{
A MademoiseLLE domain binding platform links the key RNA transporter to endosomes
}

\author{
Senthil-Kumar Devan ${ }^{1, \$}$, Stephan Schott-Verdugo ${ }^{2,3, \$}$, Kira Müntjes ${ }^{1}$, Lilli Bismar ${ }^{1}$, Jens \\ Reiners $^{4}$, Eymen Hachani ${ }^{5}$, Lutz Schmitt ${ }^{5}$, Astrid Höppner ${ }^{4}$, Sander HJ Smits ${ }^{4,5, ~ *}$, Holger \\ Gohlke $^{2,3, \text {, }}$, Michael Feldbrügge ${ }^{1, ~ *}$ \\ \$ shared first authorship \\ * shared corresponding authorship
}

${ }^{1}$ Institute of Microbiology, Heinrich Heine University Düsseldorf, Cluster of Excellence on Plant Sciences, 40204 Düsseldorf, Germany

${ }^{2}$ John von Neumann Institute for Computing (NIC), Jülich Supercomputing Centre (JSC), Institute of Biological Information Processing (IBI-7: Structural Bioinformatics), and Institute of Bio- and Geosciences (IBG-4: Bioinformatics), Forschungszentrum Jülich GmbH, WilhelmJohnen-Str., 52425 Jülich, Germany

${ }^{3}$ Institute for Pharmaceutical and Medicinal Chemistry, Heinrich Heine University Düsseldorf, Universitätsstraße 1, 40225 Düsseldorf, Germany

${ }^{4}$ Center for Structural Studies, Heinrich Heine University Düsseldorf, 40204 Düsseldorf, Germany

5 Institute of Biochemistry I, Heinrich Heine University Düsseldorf, 40204 Düsseldorf, Germany

Running title: A novel MLLE platform

Key words: Endosome / PAM2 / Poly(A)-binding protein / RNA transport / Ustilago maydis

\section{* Corresponding authors:}

Dr. Sander HJ Smits

Institute of Biochemistry,

Heinrich Heine University Düsseldorf, 40204 Düsseldorf, Germany

Phone: +49 (211) 81-12647

sander.smits@hhu.de 


\section{Dr. Holger Gohlke}

Institute for Pharmaceutical and Medicinal Chemistry,

Heinrich Heine University Düsseldorf, 40204 Düsseldorf, Germany

Phone: +49 (211) 81-13662

$\&$

John von Neumann Institute for Computing (NIC), Jülich Supercomputing Centre (JSC), Institute of Biological Information Processing (IBI-7: Structural Bioinformatics), and Institute of Bio- and Geosciences (IBG-4: Bioinformatics), Forschungszentrum Jülich GmbH, 52425 Jülich, Germany

Phone: +49 (2461) 61-85550

gohlke@uni-duesseldorf.de \& h.gohlke@fz-juelich.de

\section{Dr. Michael Feldbrügge}

Institute of Microbiology,

Bioeconomy Science Center, Cluster of Excellence on Plant Sciences

Heinrich Heine University Düsseldorf, 40204 Düsseldorf, Germany

Phone: +49 (211) 81-15475

feldbrue@hhu.de 


\section{$1 \quad$ Abstract}

2 Spatiotemporal expression is mostly achieved by transport and translation of mRNAs at defined

3 subcellular sites. An emerging mechanism mediating mRNA trafficking is microtubule-

4 dependent co-transport of mRNAs on shuttling endosomes. Although progress has been made

5 in identifying various components of the endosomal mRNA transport machinery, a mechanistic

6 understanding of how these RNA-binding proteins are connected to endosomes is still lacking.

7 Here, we demonstrate that a flexible MademoiseLLE (MLLE) domain platform within Rrm4

8 of Ustilago maydis is crucial for endosomal attachment. Our structure/function analysis

9 uncovered three MLLE domains at the C-terminus of Rrm4 with a functionally defined

10 hierarchy. MLLE3 recognizes two PAM2-like sequences of the adaptor protein Upa1 and is

11 essential for endosomal shuttling of Rrm4. MLLE1 and MLLE2 are most likely accessory

12 domains that exhibit a variant binding mode for interaction with currently unknown partners.

13 Thus, endosomal attachment of the mRNA transporter is orchestrated by a sophisticated MLLE

14 domain binding platform. 
Devan, Schott-Verdugo et al.

\section{Introduction}

mRNA localisation and local translation are essential for spatiotemporal control of protein expression. An important mechanism to achieve localised translation is the active transport of mRNAs along the cytoskeleton (Das et al., 2021; Fernandopulle et al., 2021; Mofatteh \& Bullock, 2017). Mainly, long-distance transport of mRNA is mediated by motor-dependent movement along microtubules. Important carriers are transport endosomes that move messenger ribonucleoprotein complexes (mRNPs), consisting of RNA-binding proteins and cargo mRNAs on their cytoplasmic surface (Mofatteh \& Bullock, 2017; Müntjes et al., 2021; Niessing et al., 2018). This process is evolutionarily conserved in fungi, plants, and animals (Baumann et al., 2012; Cioni et al., 2019; Tian et al., 2020a; Liao et al., 2019; Müntjes et al.., 2021; Quentin et al., 2021; Schuhmacher et al., 2021). In endosperm cells of developing rice seeds, cargo mRNAs are transported to cortical ER by the action of the two RNA recognition motif (RRM)-containing proteins RBP-P and RBP-L. These form a quaternary complex with membrane trafficking factor NSF ( $N$-ethylmaleimide-sensitive factor) and small GTPase Rab5a on the endosomal surface (Tian et al., 2020b). In neurons, mRNA transport has been linked to early and late endosomes as well as lysosomal vesicles. Especially, local translation of mRNAs encoding mitochondrial proteins on the surface of late endosomes is needed for mitochondrial function. Importantly, this trafficking process has been associated with the neuronal Charcot Marie-Tooth disease (Cioni et al., 2019). Annexin 11, a factor implicated in amyotrophic lateral sclerosis (ALS), was found as an mRNP linker on motile lysosomal vesicles (Liao et al., 2019). Recently, the five-membered FERRY complex was identified connecting mRNAs encoding mitochondrial proteins to neuronal endosomes by interaction with the active form of Rab5 (Quentin et al., 2021; Schuhmacher et al., 2021).

Among the best-studied examples for membrane-coupled mRNA transport is the endosomal mRNA transport in the corn pathogen Ustilago maydis (Béthune et al., 2019; Haag et al., 2015; Müntjes et al., 2021). Extensive peripheral movement of mRNAs is needed for efficient unipolar growth of infectious hyphae. These hyphae grow highly polarised by expanding at the growing tip and inserting regularly spaced septa at the basal pole. Loss of mRNA distribution causes aberrant bipolar growth (Baumann et al., 2012; Becht et al., 2006; Pohlmann et al., 2015). Key vehicles of cargo mRNAs are Rab5a-positive endosomes that shuttle along microtubules by the concerted action of plus-end directed kinesin- 3 and minusend directed cytoplasmic dynein (Baumann et al., 2012). Important cargo mRNAs are, for example, all four septin mRNAs. Their local translation during transport is needed to form heteromeric septin complexes on the surface of transport endosomes. Endosomes deliver these 
Devan, Schott-Verdugo et al.

complexes to the hyphal tip forming a defined gradient of septin filaments at the growing pole (Baumann et al., 2014; Olgeiser et al., 2019; Zander et al., 2016).

Rrm4 is the key RNA-binding protein of the transport process that recognises defined sets of cargo mRNAs via its three N-terminal RRMs (Fig. 1A; Olgeiser et al., 2019). Rrm4 and bound cargo mRNAs are linked to endosomes by Upa1, containing a FYVE zinc finger for interaction with $\mathrm{PI}_{3} \mathrm{P}$ lipids (phosphatidylinositol 3-phosphate; Fig 1A; Pohlmann et al., 2015; Stenmark et al., 2002). The adaptor protein contains a PAM2 motif (poly [A]-binding protein interacting motif 2; Albrecht \& Lengauer, 2004; Jinek et al., 2010; Kozlov et al., 2004) and two PAM2 like (PAM2L) sequences. These motifs are crucial for interaction with MademoiseLLE (MLLE) domains of the poly(A)-binding protein Pab1 and Rrm4, respectively (Fig. 1A; Pohlmann et al., 2015).

The MLLE domain was first identified as a conserved domain at the C-terminus of the human cytoplasmic poly(A)-binding protein 1 (PABP1C; Mangus et al., 1998; Mangus et al., 2003). Solution and crystal structures of PABC domains from PABP1C and ubiquitin ligase UBR5 showed that they are structurally conserved (Deo et al., 2001; Kozlov et al., 2001). The domain is about 70 amino acids in length and consists of five bundled $\alpha$-helices. Interaction with the PAM2 binding motif (consensus sequence $x x L N x x A x E F x P$ ) is characterised by the central $\alpha$-helix 3 with the sequence KITGMLLE and mediated by two adjacent hydrophobic pockets (Xie et al., 2014), with the binding of the Phe residue of the PAM2 motif being the major determinant for this interaction (Kozlov \& Gehring, 2010). Besides human PABPC1, there are currently only two additional proteins with MLLE domains described: the ubiquitin ligase UBR5 functioning, for example, during microRNA-mediated gene silencing ( $\mathrm{Su}$ et al., 2011) and Rrm4-type RNA-binding proteins from fungi (Fig. 1B; Müller et al., 2019).

Mutations in the C-terminal MLLE domain of Rrm4 result in the loss of Rrm4 motility, suggesting that the link to endosomes is disrupted (Becht et al., 2006). Consistently, the Cterminus of Rrm4 recognizes the PAM2L sequence of the adaptor protein Upa1 (Pohlmann et al., 2015), suggesting that the interaction of MLLE domains with PAM2L sequences is responsible for its endosome association. In this study, we combine structural biology with fungal genetics to demonstrate that the C-terminal half of Rrm4 has three divergent MLLE domains with a flexible arrangement that contribute differentially to the endosomal attachment. 
bioRxiv preprint doi: https://doi.org/10.1101/2021.10.25.465676; this version posted October 25, 2021. The copyright holder for this preprint (which was not certified by peer review) is the author/funder, who has granted bioRxiv a license to display the preprint in perpetuity. It is made available under aCC-BY-NC 4.0 International license.

Devan, Schott-Verdugo et al.

\section{Results}

\section{Iterative structural modeling predicts three MLLE domains at the C-terminus of Rrm4}

To generate structural models of the MLLE domains present in Rrm4, we focused on the Cterminal part of the protein (residues 421 to 792). This excluded the three N-terminal RRMs but included the previously predicted two C-terminal MLLE domains (Fig. 1A-B; Müller et al., 2019). Subjecting this Rrm4 sequence region to iterative comparative modeling with TopModel (Fig. 1C; Mulnaes et al., 2020a) revealed, as expected, the previously identified two regions with homology for MLLE domains located at residues 571-629 and 712-791 (denoted MLLE2 and MLLE3; Fig. 1C; Müller et al., 2019). Unexpectedly, using the TopModel workflow with its efficient template selection capabilities (Mulnaes et al., 2020a), we identified an additional de novo predicted MLLE domain located at residues 451-529 (denoted MLLE1; Fig. 1B-C; Fig. EV1A). Although the sequence identity between templates and their respective Rrm4 sequence stretches is only 17 to $32 \%$ (Fig. 1B, Fig. EV1A), the generated MLLE domain models have a high predicted local structural quality, as assessed by TopScore (Fig. 1C; Mulnaes \& Gohlke, 2018). The generated models were also verified by the current deep neural network modeling approaches AlphaFold2 and RoseTTAFold (Fig. EV1B; Baek et al., 2021; Jumper et al., 2021), further indicating that the C-terminal half of Rrm4 has three MLLE domains instead of the previously identified two. All of these MLLE domains might be relevant for the interaction with Upa1.

\section{X-ray analysis of the second MLLE domain confirms the predicted structural models}

To verify the structural models further, we expressed and purified an N-terminally truncated version of the Rrm4 carrying the three MLLE domains in Escherichia coli (Fig. EV2A; version H-Rrm4-NT4 carrying an N-terminal hexa-histidine tag; Pohlmann et al., 2015; Materials and methods). Size exclusion chromatography combined with multiangle light scattering (MALS) indicates that the protein is homogenous and does not form aggregates (Fig. EV2B-C). We thus set out to crystallize the protein for X-ray diffraction analysis (see Material and Methods). Testing 2016 different conditions, crystals were only obtained in individual cases after at least 7 days of incubation. A complete dataset was collected from a single crystal diffracting to $2.6 \AA$ resolution and a $\mathrm{P}_{3} 2_{1} 2$ symmetry. Data and refinement statistics are given in Appendix Table S2. Surprisingly, the unit cell dimensions were small and, with a Matthews coefficient assuming $50 \%$ solvent content, only 128 amino acids would fit into the asymmetric unit of the crystal. Hence, the unit cell has an insufficient size to cover H-Rrm4-NT4, which contains 380 amino 
Devan, Schott-Verdugo et al.

acids. Using the predicted models of MLLE1-3 as templates for molecular replacement, only MLLE2 gave a clear solution, showing after refinement that two copies of MLLE2 (residues 567-630) were present in the asymmetric unit. For comparison, previously, two copies of the MLLE domain in the asymmetric unit were reported in crystals of MLLE of UBR5 (MunozEscobar et al., 2015). The structural data indicates that the protein was truncated from both termini during crystallization, resulting in a shortened version of the H-Rrm4-NT4 protein that formed stable crystals (see Material and methods). Both MLLE2 ${ }^{\mathrm{Rrm} 4}$ copies adopt the same overall fold (Fig. 2A) as seen by the RMSD of $0.29 \AA$ over 59 C-alpha atoms. The MLLE2 ${ }^{\text {Rrm4 }}$ crystal structure displays high similarity with the MLLE domain of the ubiquitin ligase UBR5 (MLLE ${ }^{\text {UBR5; }}$ Munoz-Escobar et al., 2015; PDB code 3NTW, RMSD of $0.97 \AA$ over 56 amino acids) and the MLLE domain of PABPC1 (Kozlov et al., 2010; PDB code 3KUS, RMSD of $1.34 \AA$ over 61 amino acids). The MLLE2 ${ }^{\mathrm{Rrm} 4}$ domain consists of four helices (designated $\alpha 2$ 5; Fig. 2A) that are arranged as a right-handed superhelix similar to MLLE ${ }^{\mathrm{UBR} 5}$. In comparison to the MLLE domain of PABPC1, the first short helix is absent in both MLLE2 ${ }^{\text {Rrm4 }}$ and MLLE $^{\mathrm{UBR} 5}$ structures.

When comparing the obtained crystal structure with the MLLE2 ${ }^{\mathrm{Rrm} 4}$ model generated by TopModel, the average RMSD is $0.62 \AA$ over the backbone atoms, close to the uncertainty of the atomic coordinates of the experimental structure (Fig. 2B). Importantly, this confirms our structural model of MLLE2 ${ }^{\text {Rrm4 }}$ and strongly suggests that the modeled MLLE1 ${ }^{\text {Rrm4 }}$ and MLLE $3^{\text {Rrm4 }}$ domains should be of equally high quality.

We compared the models obtained of MLLE1-3 ${ }^{\mathrm{Rrm} 4}$ with the known structure of the human PABPC1 focusing on the well described PAM2 peptide binding pocket. This revealed that MLLE3 ${ }^{\text {Rrm4 }}$ maintains a characteristic Gly residue at position 736 that binds the conserved Phe residue of the PAM2 motifs, a major binding determinant in PABPC1 and UBR5 (Kozlov \& Gehring, 2010; Munoz-Escobar et al., 2015; Fig. 2C). However, the binding interfaces of MLLE1 $^{\text {Rrm4 }}$ and MLLE2 ${ }^{\text {Rrm4 }}$ are altered compared to the 'canonical' binding site in PABPC1 and UBR5 (Fig. 2C). Instead of Gly, MLLE1 ${ }^{\text {Rrm4 }}$ and MLLE2 ${ }^{\text {Rrm4 }}$ have a Ser and Arg in the corresponding positions 471 and 573. The notion that MLLE1 ${ }^{\mathrm{Rrm} 4}$ and MLLE2 ${ }^{\mathrm{Rrm} 4}$ may differ from canonical MLLE domains is also supported by the lower sequence identity of MLLE1 ${ }^{\text {Rrm4 }}$ and MLLE2 ${ }^{\text {Rrm4 }}$ when compared to previously characterized MLLE domains (Fig. EV1A). In summary, structural modeling revealed the presence of three MLLE domains at the C-terminus of Rrm4. Furthermore, the structure of the MLLE2 ${ }^{\text {Rrm4 }}$ domain was successfully verified by Xray crystallographic analysis. MLLE1 ${ }^{\mathrm{Rrm} 4}$ and $M L L E 2^{\mathrm{Rrm} 4}$ are divergent in the key region of 
bioRxiv preprint doi: https://doi.org/10.1101/2021.10.25.465676; this version posted October 25, 2021. The copyright holder for this preprint (which was not certified by peer review) is the author/funder, who has granted bioRxiv a license to display the preprint in perpetuity. It is made available under aCC-BY-NC 4.0 International license.

Devan, Schott-Verdugo et al.

145 PAM2 binding, suggesting that these domains might employ a different binding mode or show

146 a different binding specificity.

147 The MLLE domains of Rrm4 form a binding platform with flexible arrangement of the individual domains

149 To study the relative arrangement of all three MLLE ${ }^{\mathrm{Rrm} 4}$ domains and the orientation to the N-

150 terminal RRMs, we performed Small-Angle X-ray Scattering (SAXS) experiments. We expressed and purified H-Rrm4-NT4 as well as full-length protein with N-terminal GST fusion (glutathione S-transferase; G-Rrm4) from E. coli (see Materials and methods). Primary data analysis of the scattering curves (Tria et al., 2015) revealed that both proteins are monomeric and highly flexible in solution (Appendix Table S3; Fig. 2D-E; Fig. EV2D-E). To visualise the different conformations, we performed an Ensemble Optimization Method (EOM) analysis for both the G-Rrm4 and H-Rrm4-NT4 proteins (Fig 2D-E). We used our MLLE models and a GST model (PDB entry: 1ua5) together with the protein sequence for G-Rrm4 as input, yielding a distribution of different conformations of the protein in solution (representative models in Fig. EV2E). One model of G-Rrm4, representing $25 \%$ of the population, revealed that the Cterminal part containing MLLE1-3 ${ }^{\mathrm{Rrm} 4}$ adopts an elongated and mainly unfolded but open conformation (Fig. 2D; Fig. EV2D-E). The N-terminal part, containing RRM domains of the GST fusion protein, adopts a more globular structure, indicating less flexibility within this region (Fig. 2D; Fig. EV2D-E). Studying only the C-terminal part of Rrm4 revealed that the most prominent model of this analysis ( $75 \%$ of the population) has a nearly identical conformation as the one selected for G-Rrm4 (Fig. 2D-E, Fig. EV2E). It suggests that the Cterminal part of Rrm4-NT4 adopts a very similar orientation when expressed by itself. From this analysis, one can deduce that the MLLE1-3 ${ }^{\mathrm{Rrm} 4}$ domains form a C-terminal binding platform with a flexible arrangement for multiple contact sites for binding partners. The RRM domains and thus the RNA interaction site are clearly spatially separated from the protein interaction platform.

\section{The third MLLE is essential for interaction with PAM2 like sequences of Upa1}

172 To evaluate the interaction capacity of MLLE1-3 $3^{\mathrm{Rrm} 4}$, we performed in vitro binding studies.

173 We expressed different deletion versions of Rrm4 as N-terminal GST fusions in E. coli. As a 174 control, we expressed an N-terminal GST fusion of the MLLE domain of Pab1 (Fig. 3A; 175 Materials and methods). To check the physical interaction with PAM2 and PAM2L sequences 176 of Upa1, we expressed 18 amino acid fragments (Fig. 3A, Fig. EV3B) as N-terminal hexa177 histidine-SUMO (HS) fusion proteins (see Materials and methods). In GST pull-down 
Devan, Schott-Verdugo et al.

experiments using GST fusion proteins as bait, G-Pab1-MLLE interacts with HS-PAM2 but not with the HS-PAM2L motifs of Upa1 (Fig. EV3B, lane 2). Conversely, G-Rrm4-NT4 recognizes the two HS-PAM2L motifs of Upa1 but not the HS-PAM2 motif(Fig. EV3B, lane 3; Pohlmann et al., 2015). Interestingly, the interaction with both PAM2L motifs was lost when MLLE3 $^{\text {Rrm4 }}$ was deleted (G-Rrm4-NT4-M3A; Fig. EV3B, lane 6), while constructs with deletion of MLLE1 ${ }^{\mathrm{Rrm} 4}$ or MLLE2 ${ }^{\mathrm{Rrm} 4}$, or MLLE $1^{\mathrm{Rrm} 4}$ and $\mathrm{MLLE}^{\mathrm{Rrm}}{ }^{4}$, still interacted with the HS-PAM2L motifs of Upa1 (Fig. EV3B, lane 4,5 and 7).

To obtain quantitative data on the protein/peptide interactions, we performed isothermal titration calorimetry (ITC) experiments with purified proteins (Fig. EV3C) using synthetic peptides with a length of 18 amino acids (PAM2 ${ }^{\mathrm{Upa} 1}$, PAM2L1 ${ }^{\mathrm{Upa} 1}$, and PAM2L2 ${ }^{\text {Upa1 }}$; Fig. 3A). From the curves, the binding constant $K_{\mathrm{D}}$ and the binding stoichiometry was calculated, which in all cases indicated a 1:1 ratio between the G-Rrm4-NT4 protein and the binding partner.

Testing G-Pab1-MLLE with the peptides revealed a $K_{\mathrm{D}}$ of $14.6 \mu \mathrm{M}$ for PAM2 ${ }^{\text {Upa1 }}$ (Fig. EV3D), which is within the range of observed $K_{\mathrm{D}}$ of 0.2 to $40 \mu \mathrm{M}$ for known MLLE/PAM2 interactions like the MLLE domain of PABPC1 with various PAM2 sequences (Mattijssen et al., 2021). Testing G-Pab1-MLLE with PAM2L1 ${ }^{\text {Upa1 }}$ and PAM2L2 ${ }^{\text {Upa1 }}$ peptides, no indication for binding was observed. PAM2L sequences are rich in acidic residues and exhibit a different FxxP spacing than the canonical FXP sequence of PAM2 sequences in the core region (Fig. 3A, EV3D; see Discussion). The observed binding behaviour indicates a clear binding specificity differentiating PAM2 and PAM2L peptides. This is in line with the previously published GST pull-down experiments (Pohlmann et al., 2015).

In comparison, testing G-Rrm4-NT4 with the peptides revealed a $K_{\mathrm{D}}$ of $14.9 \mu \mathrm{M}$ for PAM2L1 ${ }^{\mathrm{Upa} 1}$ and $5.1 \mu \mathrm{M}$ for PAM2L2 ${ }^{\mathrm{Upa} 1}$ and no binding to PAM2 ${ }^{\mathrm{Upa} 1}$ (Fig. 3B). This suggests a similar affinity when compared to the interactions of MLLE ${ }^{\mathrm{Pab} 1}$ with PAM2 and demonstrates the high sequence specificity of the MLLE domains to their respective PAM2L sequences (see Discussion).

Analysing G-Rrm4-NT4-M3 $\Delta$ with a deletion of MLLE3 ${ }^{\mathrm{Rrm} 4}$ revealed that binding to PAM2L1 ${ }^{\text {Upa1 }}$ and PAM2L2 ${ }^{\text {Upa1 }}$ was no longer detectable (Fig. 3C). This is in line with observations from the GST pull-down experiments (Fig. EV3B). This suggests that MLLE3 ${ }^{\text {Rrm4 }}$ is essential for binding. Testing G-Rrm4-NT4 versions carrying deletions in MLLE1 ${ }^{\text {Rrm4 }}$ and MLLE2 ${ }^{\text {Rrm4 }}$ revealed no difference in binding affinity (Fig. EV3E-F). Even testing G-Rrm4NT4 with both MLLE domains deleted revealed a binding affinity in the same range as the wildtype version containing all three MLLEs (Fig. 3D). We conclude that (i) MLLE3 ${ }^{\text {Rrm4 }}$ is vital for recognizing PAM2L sequences with a higher affinity to PAM2L2 and (ii) neither 
bioRxiv preprint doi: https://doi.org/10.1101/2021.10.25.465676; this version posted October 25, 2021. The copyright holder for this preprint (which was not certified by peer review) is the author/funder, who has granted bioRxiv a license to display the preprint in perpetuity. It is made available under aCC-BY-NC 4.0 International license.

Devan, Schott-Verdugo et al.

MLLE1 $^{\text {Rrm4 }}$ nor MLLE2 ${ }^{\text {Rrm4 }}$ contribute to the binding of PAM2L or PAM2 motifs. This is consistent with our structural analysis revealing a differences in the binding site for these MLLE domains (see Discussion).

\section{The third MLLE domain of Rrm4 is essential for its function}

217 To address how the different MLLE domains contribute to the biological function of Rrm4, we generated $U$. maydis strains carrying deletions in the respective domains of Rrm4 (Fig. 4A). As genetic background, we used laboratory strain AB33, expressing the heteromeric master transcription factor of hyphal growth $(\mathrm{bE} / \mathrm{bW})$ under control of the nitrate inducible promoter $\mathrm{P}_{\text {narl }}$. Thereby, polar hyphal growth can be elicited efficiently and in a highly reproducible fashion by changing the nitrogen source (Fig. 4B, top; Brachmann et al., 2001). To investigate dynamic endosomal transport, we used strains expressing functional C-terminal fusion Upa1Gfp and Rrm4-Kat (fusion with enhanced version of the green fluorescent protein, Clontech, and monomeric version of red fluorescent protein mKate2, respectively; Müntjes et al., 2020; Pohlmann et al., 2015; see Materials and methods).

The resulting hyphae grew with a defined axis of polarity, i.e., they expanded at the hyphal tip and inserted basal septa leading to the formation of empty sections (Fig. 4B-C). Loss of Rrm4 (rrm4 4 strain) caused the formation of hyphae growing at both ends, characteristic for aberrant bipolar growth (Fig. 4B-C; Pohlmann et al., 2015). Testing Rrm4-Kat versions carrying deletions of MLLE1 ${ }^{\mathrm{Rrm} 4}$ or MLLE2 ${ }^{\mathrm{Rrm} 4}$ did not cause alterations in unipolar growth (Fig. 4B-C). Furthermore, endosomal shuttling and co-localisation were indistinguishable from wildtype (Fig. 4D-E). Also, the number of Rrm4-Kat-positive endosomes (number of signals / $10 \mu \mathrm{m}$, Fig. EV4A), velocity, and processivity (Fig. EV4B-C) were comparable to wildtype. Hence, the first two MLLE domains were dispensable for polar growth and endosomal shuttling under optimal growth conditions. Since the deletion of the first two MLLEs did not substantially alter the function of Rrm4, we can infer that the deletion neither affects the overall structure of the protein nor interfere with other domains like the RNA-binding domain of the protein. This supports the conclusions of our biochemical experiments (see above).

Importantly, testing strains expressing Rrm4-Kat with deletion of the third MLLE domain revealed a loss-of-function phenotype similar to $r r m 4 \Delta$ strains. The amount of bipolar hyphae was comparable to $r r m 4 \Delta$ strains (Fig. 4B-C; Becht et al., 2006). We observed drastic alteration in shuttling, and Rrm4 aggregates did not co-localise with motile Upa1-positive signals (Fig. 4D-E). While the Rrm4 signals were static (Fig. 4D-E; Fig. EV4A-C) the amount of motile 
Devan, Schott-Verdugo et al.

Upa1-Gfp positive endosomes, their velocity, and their processivity were not affected (Fig. EV4A-C, summarised in Fig. EV4D). This is consistent with previous results showing that the third MLLE domain is important for the movement of Rrm4 and that endosomal shuttling of Upal is not affected if Rrm4 is missing (Baumann et al., 2012; Becht et al., 2006). To conclude, MLLE3 ${ }^{\text {Rrm4 }}$ is an essential domain for Rrm4 attachment to endosomes in contrast to MLLE1 and MLLE2 ${ }^{\text {Rrm4 }}$.

\section{The second MLLE domain plays accessory roles in endosomal Rrm4 attachment}

To investigate the biological role of MLLE1 ${ }^{\mathrm{Rrm} 4}$ and MLLE2 ${ }^{\mathrm{Rrm} 4}$ in more detail, we generated strains expressing Rrm4-M12 $\Delta$-Kat, lacking MLLE1 ${ }^{\text {Rrm4 }}$ and MLLE2 ${ }^{\text {Rrm4 }}$ domains, and tested the influence on hyphal growth. Unipolar growth was not disturbed (Fig. 5A-B). To challenge endosomal attachment of Rrm4, we expressed Upa1-Gfp versions carrying mutations in PAM2L motif 1 or 2 as well as in both motifs; these motifs are important for Rrm 4 interaction

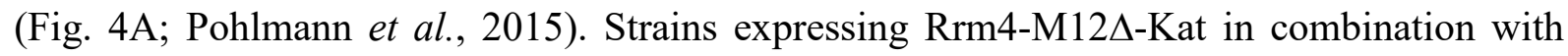
mutated PAM2L1 or PAM2L2 of Upa1 showed unipolar growth comparable to wildtype (Fig. $5 \mathrm{~A}-\mathrm{B})$, indicating that $\mathrm{MLLE}^{\mathrm{Rrm} 4}$ and $\mathrm{MLLE}^{\mathrm{Rrm} 4}$ are dispensable for unipolar growth even when the endosomal attachment was weakened by expressing Upal versions with mutated PAM2L motifs (Fig. EV4D). When studying Upal mutated in both PAM2L motifs, we observed an aberrant bipolar growth phenotype comparable to the upal $\Delta$ strain (Fig. 5A-B). This was expected, since the interaction of Rrm4 to endosomes is mediated by both PAM2L

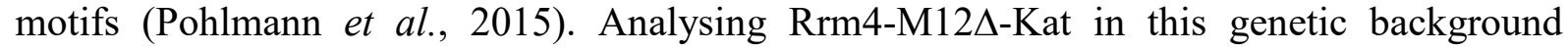
revealed no additive phenotype (Fig. 5A-B). This reinforces that the interactions of PAM2L motifs of Upal are the major determinants for endosomal attachment of Rrm4.

Next, we investigated endosomal shuttling. In strains expressing Rrm4-M12 $\Delta$-Kat missing MLLE1 ${ }^{\text {Rrm4 }}$ and MLLE2 ${ }^{\text {Rrm4 }}$ endosomal shuttling was not disturbed (Fig. 5C). The amount of motile Rrm4-M12 $\Delta$-Kat positive signals, their velocity, and their processivity were not affected (Fig. EV5A). Like above, we challenged endosomal attachment of Rrm4 by expressing Upa1 versions with mutations in the PAM2L motifs. As expected, simultaneous mutation of both PAM2L motifs of Upa1 resulted in a reduction in the number of Rrm4-Kat positive shuttling endosomes (Fig. 5C, EV5E; Pohlmann et al., 2015). In about 80\% of hyphae, Rrm4-Kat found to be aberrantly attached to microtubules (MT) when both PAM2L motifs are mutated (Fig. 5C-D). This is a characteristic feature for altered endosomal attachment of Rrm4 due to the 
Devan, Schott-Verdugo et al.

static accumulation of Rrm4-Kat, which can be also seen in upald strains (Fig. EV5C; Jankowski et al., 2019).

To analyse the influence of individual PAM2L motifs we determined the amount of hyphae with aberrant microtubule staining in strains co-expressing Rrm4-Kat and an Upa1-Gfp version with mutations of PAM2L sequence 1 or 2 (Fig. 5D). Mutations in PAM2L1 and PAM2L2 causes $8 \%$ and $19 \%$ of hyphae with aberrant MT staining, respectively. This indicates that the interaction of PAM2L2 is more important for correct endosomal attachment of Rrm4. This is consistent with our biochemical results demonstrating that MLLE3 $^{\text {Rrm4 }}$ binds stronger to PAM2L2 of Upa1 than to PAM2L1 (Fig. 3D).

Next, we investigated the association of Rrm4-M12 $\Delta$-Kat in strains expressing Upa1PAM2L1. Thus, the endosomal attachment was solely dependent on the interaction of MLLE3 $^{\text {Rrm4 }}$ with the PAM2L2 sequence of Upa1. We did observe $6 \%$ of hyphae with aberrant MT staining (Fig. 5D; Fig. EV4D). This was comparable to strains expressing Rrm4-Kat suggesting no clear difference (Fig. 5D). However, testing Upa1 with its PAM2L2 mutated, leaving only PAM2L1 for interaction with Rrm4, we observed a clear increase in hyphae with aberrant MT staining when comparing strains co-expressing Rrm4-M12 $\Delta$-Kat versus Rrm4Kat (52\% versus 19\%; Fig. 5D-E). Hence, the region covering MLLE1 ${ }^{\text {Rrm4 }}$ and MLLE2 ${ }^{\text {Rrm } 4}$ was important for Rrm4 attachment. Finally, we tested individual deletions in MLLE1 ${ }^{\text {Rrm4 }}$ and MLLE2 ${ }^{\text {Rrm4 }}$ in combination with mutated PAM2L2 in Upa1 to dissect the role of the different MLLE domains. In the strains expressing Rrm4-Kat or Rrm4-M1 $\Delta$-Kat, the amount of hyphae with aberrant MT staining was comparable (18\% versus 11\%, respectively; Fig. 5D). However, strains expressing Rrm4-M2 $\Delta$-Kat exhibited an increased amount of hyphae with aberrant MT staining that was comparable to Rrm4-M12 $\Delta$-kat (51\% versus 52\% respectively; Fig. 5D; Fig. EV4D). To conclude, for MLLE1 ${ }^{\mathrm{Rrm} 4}$ we were unable to assign a clear function yet. However, MLLE2 ${ }^{\text {Rrm4 }}$ plays an accessory role in the endosomal attachment of Rrm4. In essence, the Cterminus of Rrm4 contains three MLLE domains, with MLLE2 ${ }^{\text {Rrm4 }}$ fulfilling an accessory role and MLLE3 having an essential function during the attachment of mRNPs to endosomes.

\section{Discussion}

Combining structural biology and biophysical techniques with fungal genetics and cell biology, we addressed how mRNPs can be mechanistically linked to endosomes in the model fungus $U$. maydis. Previously, it was found that the C-terminal MLLE domain of Rrm4 is needed for shuttling (Becht et al., 2006) and that the C-terminus of Rrm4 interacts with two PAM2L motifs of Upal (Pohlmann et al., 2015). Now, we demonstrate that the C-terminus of Rrm4 contains not only two MLLE domains, but a sophisticated binding platform consisting of three MLLE 
Devan, Schott-Verdugo et al.

311 domains that collaborate for optimal functionality in linking the key RNA transporter to endosomes. We disclose a strict hierarchy with main and accessory domain. The accessory MLLE2 domain shows variations in the critical region of the predicted PAM2 binding pocket, suggesting a novel mode of interaction with currently unknown interaction partners. To the best of our knowledge, Rrm4 represents the first protein containing multiple MLLE domains to form a binding platform. This interaction unit is essential for correct endosomal attachment and, hence, mRNP trafficking.

\section{The MLLE / PAM2 connection}

319 The founding member of the MLLE domain family is present at the C-terminus of the poly(A)binding protein PABPC1. This domain interacts with PAM2 motifs of numerous interaction partners such as GW182, eRF3, and the RNA-binding protein LARP4 functioning in microRNA biology, translational termination, and posttranscriptional control, respectively (Jinek et al., 2010; Kozlov \& Gehring, 2010; Yang et al., 2011). Structural analysis revealed a common mode of binding, where the Leu and particularly the Phe of the PAM2 consensus motif xxLNxxAxEFxP (Fig. EV3A) are interacting with helix 2 and 3 as well as helix 3 and 5 of MLLE domain, respectively (Kozlov \& Gehring, 2010; Xie et al., 2014). Indeed, the interaction of MLLE with a hydrophobic amino acid is highly conserved, which in most cases is Phe with a known exception in the variant PAM2 $\mathrm{w}$ motif of LARP4 and LARP4A, where Trp is found (Fig. EV3A; Grimm et al., 2020; Yang et al., 2011; Xie et al., 2014).

Studying the MLLE domain-containing protein Rrm4, we discover that the protein has three MLLE domains in its C-terminal half. MLLE $3^{\text {Rrm4 }}$ binds PAM2L motifs of Upa1 with a $K_{\mathrm{D}}$ of 5 and $15 \mu \mathrm{M}$ for PAM2L2 ${ }^{\mathrm{Upa} 1}$ and -1, respectively. The binding affinities are in the same range as described for other MLLE/PAM2 interactions: for example, the binding of MLLE $^{\text {PABPC1 }}$ with PAM2 ${ }^{\text {LARP1 }}$, PAM2 ${ }^{\text {Tob2-125 }}$, PAM2 ${ }^{\text {LARP4 }}$ exhibit a $K_{\mathrm{D}}$ of $3.8,16$ and $22 \mu \mathrm{M}$, respectively (Mattijssen et al., 2021). Importantly, our biophysical assessment confirms the exquisite binding specificity of $\mathrm{MLLE}^{\mathrm{Rrm} 4}$ that recognizes PAM2L1 ${ }^{\mathrm{Upa} 1}$ and -2 but not PAM2 ${ }^{\mathrm{Upa} 1}$ version. PAM2L sequences contain a stretch of acidic amino acids in the N-terminal half, and the spacing of FxxP in the core sequence is altered (Fig. EV3A). These variations might account for the differential binding mode. Visual inspection of the potential PAM2L binding region in the predicted model revealed that MLLE3 ${ }^{\mathrm{Rrm} 4}$ contains a Gly at position 736 to sustain the binding of an aromatic residue of PAM2L as described for other MLLE domains

342 (see above). However, we were unable to uncover the structural basis for the sequence 
Devan, Schott-Verdugo et al.

specificity. Towards this end, future structural studies are required to provide detailed information on the interaction of MLLE3 ${ }^{\text {Rrm4 }}$ with PAM2L sequences.

Differential PAM2 binding has also been described for the MLLE ${ }^{\mathrm{UBR} 5}$. This MLLE domain interacts with PAM2 ${ }^{\text {PAIP }}$ with an affinity of $3.4 \mu \mathrm{M}$ (Lim et al., 2006), whereas it binds a PAM2L sequence (Fig. EV3A) in its own HECT domain with lower affinity $\left(K_{\mathrm{D}}\right.$ of $\left.50 \mu \mathrm{M}\right)$. The latter interaction has been implicated in the regulation of the HECT ligase activity (MunozEscobar et al., 2015). Interestingly, the PAM2L sequence within the HECT domain of UBR5 is highly similar to the PAM2L1 and -2 of Rrm4: (i) the sequences contain an acidic stretch Nterminal to the conserved Phe (Fig. EV3A), (ii) the distance between Phe and Pro is two instead of one amino acid, and (iii) the PAM2L sequence contains an additional bulky Tyr in close vicinity to the Phe residue. Remarkably, MLLE ${ }^{\mathrm{PABC} 1}$ does not recognise the PAM2L sequence of UBR5 (Munoz-Escobar et al., 2015). In essence, although the strong sequence specificity of MLLE $^{\mathrm{Rrm} 4}$ and MLLE ${ }^{\mathrm{Pab} 1}$ from U. maydis is, to the best of our knowledge, so far unique, we hypothesise that differential PAM2 and PAM2L interactions are evolutionarily conserved and might be more widespread than currently anticipated.

We observed also clear binding specificity for MLLE ${ }^{\mathrm{Pab} 1}$ from $U$. maydis that interacts with PAM2 ${ }^{\text {Upa1 }}$ but not the PAM2L sequences from Upa1 (Fig. 6). MLLE ${ }^{\text {Pab1 }}$ binds with comparable affinity to the PAM2 ${ }^{\mathrm{Upa} 1}$ ( $K_{\mathrm{D}}$ of about $14 \mu \mathrm{M}$, Fig EV3D). Previously, we showed that mutations in PAM2 ${ }^{\mathrm{Upa} 1}$ strongly decreased MLLE ${ }^{\mathrm{Pab} 1}$ binding but did not interfere with the endosomal shuttling of Pab1 (Pohlmann et al., 2015). Thus, there might be other members of the endosomal mRNPs interacting with Pab1 and stabilising its endosomal association. In fact, the dimerising scaffold protein Upa2 of endosomal mRNA transport contains four PAM2 motifs offering eight potential PAM2 motifs for interaction with Pab1 (Fig. 6). However, mutating all four PAM2 motifs did not interfere with endosomal mRNA transport, although interaction with MLLE ${ }^{\text {Pab1 }}$ was lost (Jankowski et al., 2019), confirming a potential redundancy. Consistently, mutations in PAM2 of human LARP4B did not interfere with the function of stress granule recruitment, also suggesting in this case the presence of additional factors (Grimm et al., 2020).

Studying the other two MLLE domains of Rrm4 revealed that both lack the canonical Gly for interactions with PAM2 or PAM2L sequences. MLLE1 ${ }^{\text {Rrm4 }}$ and MLLE2 ${ }^{\text {Rrm4 }}$ have Ser471 and Arg573 instead, respectively. Consistently, MLLE1 ${ }^{\text {Rrm4 }}$ and MLLE2 ${ }^{\text {Rrm4 }}$ do not bind PAM2 or PAM2L sequences. Thus, although the general fold of the MLLE domain is probably conserved in MLLE1 ${ }^{\mathrm{Rrm} 4}$ and MLLE2 ${ }^{\mathrm{Rrm} 4}$, these domains most likely exhibit a different binding specificity to their potential protein partner. Our detailed in vivo analysis revealed that MLLE2 carries out an accessory function for the correct attachment of Rrm4 during endosomal 
Devan, Schott-Verdugo et al.

shuttling. In case of MLLE1 we did not identify a clear function so far. However, we believe that all three MLLE domains are functional important. This is supported by the fact that the presence of a MLLE binding platform with three MLLE domains is evolutionarily conserved. Even Rrm4 versions of the distantly related fungus Rhizophagus irregularis contains three MLLE domains (Mucoromycota, determined by AlphaFold; Müller et al., 2019).

Studying the spatial arrangement of the three MLLE domains revealed that they form a highly flexible binding platform. This would allow for the simultaneous interaction of several binding partners and potential rearrangements like an induced fit after binding. Such a scenario might be particularly important during the loading and unloading of mRNPs to endosomes. Noteworthy, the N-terminal RNA-binding domain consisting of three RRMs is clearly separated from the MLLE domains for endosomal attachment. This is comparable with the arrangement of RRM and MLLE domains in human PABPC1: the four N-terminal RRM domains interact with the poly(A) tail of mRNAs, and the MLLE domain is exposed by a flexible spacer region for protein/protein interactions (Schäfer et al., 2019). Within the spacer region, additional interactions with the RRM2 of PABPC1 were found, suggesting a function in multimerization of the protein on the poly(A) tail of mRNAs (Sawazaki et al., 2018).

\section{Conclusion}

Endosomal mRNA transport is evolutionarily highly conserved. Besides hyphal growth in fungi, it is important for endosperm development in plants as well as neuronal functions in animals and humans (Béthune et al., 2019; Fernandopulle et al., 2021; Müntjes et al., 2021; Tian et al., 2020a). Malfunction causes defects in polar growth in fungi and has been implicated in neuronal diseases such as Charcot-Marie-Tooth type 2B neuropathy or amyotrophic lateral sclerosis in humans (Cioni et al., 2019; Liao et al., 2019).

A key question is how mRNPs are linked to endosomes. In plants, two RRM-type RNA-binding proteins form a complex with cargo mRNAs and the endosomal component $N$-ethylmaleimidesensitive factor NSF as well as Rab5a (Tian et al., 2018; Tian et al., 2020a; Tian et al., 2020b).

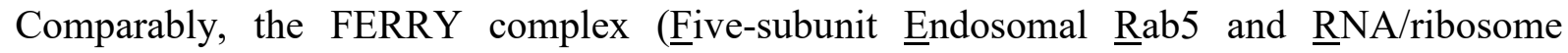
intermediarY) interacts with the activated GTP-bound form of Rab5 during endosomal mRNA transport in neurons (Schuhmacher et al., 2021; Quentin et al., 2021). Further examples are the membrane-associated protein Annexin 11 that functions in linking large RNA granules to lysosomal vesicles during mRNA transport in axons and dendrites (Liao et al., 2019). Thus, a number of components and interactions are known, however detailed structural insights are scarce. Here, we demonstrate that in hyphae, endosomal attachment of Rrm4 is mediated by an 
Devan, Schott-Verdugo et al.

410 MLLE binding platform with a non-canonical accessory domain joining an essential MLLE 411 domain for perfect interaction to Upal on the endosomal surface (Fig. 6). This binary 412 interaction in the core of the transport mRNPs is supported by numerous interactions of 413 additional protein partners such as Upa2 and Pab1 that assist in the attachment of components 414 to the endosomal surfaces (Fig. 6). In essence, studying endosomal mRNP transport in fungal 415 model systems might guide future research endeavours in plant and neuronal systems. 
Devan, Schott-Verdugo et al.

\section{Materials and methods}

\section{Structural modeling of C-terminal MLLE domains of Rrm4}

419 To obtain structural models of the C-terminal region of Rrm4, an iterative homology modeling

420 approach was used with the TopModel workflow (Mulnaes et al., 2020a). Initially, the complete 421 C-terminal region (421 to 792) was submitted as input in TopModel and identified templates 422 for MLLE3 ${ }^{\text {Rrm4 }}$ (665 - 792 AA; Fig. 1C, Fig. EV1A). Then, the rest of the C-terminal part comprising amino acids 421 to 664 was resubmitted as input and identified other templates as 424 a new starting point for the $\operatorname{MLLE}^{\mathrm{Rrm} 4}$ (571-629). Likewise, the remaining C-terminal 425 sequence comprising amino acids 421 to 549 was resubmitted as input, which identified other 426 templates as a new starting point for the $\operatorname{MLLE1}^{\mathrm{Rrm} 4}$ (446-530). In total, this led to the 427 identification of three MLLE domains, for which structural models were generated using 428 default TopModel parameters. The quality of the structural models was assessed with TopScore 429 (Mulnaes \& Gohlke, 2018).

\section{$430 \quad$ Plasmids, strains, and growth conditions}

431 For molecular cloning of plasmids, Escherichia coli Top10 cells (Thermofisher C404010) and 432 for recombinant protein expression E.coli Lobstr cells (Kerafast EC1002) were used 433 respectively. Sequence encoding H-Rrm4-NT4 was subcloned into pET22 vector (Merck 69744) with an N-terminal hexa-histidine tag for crystallization studies. Sequence encoding MLLE variants were inserted into pGEX-2T vector (Merck GE28-9546-53) containing GST sequence in N-terminus for pulldown and ITC experiments. Sequence encoding PAM2 variants were inserted into Champion pET-Sumo vector (Thermofisher K30001). pRarepLys plasmid was co-transformed in E. coli Lobstr strain to supplement the rare codons for efficient recombinant protein production. E. coli transformation, cultivation, and plasmid isolation were conducted using standard techniques. All U. maydis strains are derivatives of AB33, in which hyphal growth can be induced by switching the nitrogen source in the medium (Brachmann et al., 2001). U. maydis yeast cells were incubated in complete medium (CM) supplemented with $1 \%$ glucose, whereas hyphal growth was induced by changing to nitrate minimal medium (NM) supplemented with $1 \%$ glucose, both at $28^{\circ} \mathrm{C}$ (Brachmann et al., 2001). Detailed growth conditions and general cloning strategies for U. maydis are described elsewhere (Baumann et al., 2012; Brachmann et al., 2004; Terfrüchte et al., 2014). All plasmids were verified by sequencing. Strains were generated by transforming progenitor strains with linearized plasmids.

448 Successful integration of constructs was verified by diagnostic PCR and by Southern blot 
Devan, Schott-Verdugo et al.

analysis (Brachmann et al., 2004). For ectopic integration, plasmids were linearized with SspI and targeted to the $i p^{\mathrm{S}}$ locus (Loubradou et al., 2001). A detailed description of all plasmids, strains, and oligonucleotides is given in Appendix Tables S3-S7. Sequences are available upon request.

\section{Recombinant protein expression and purification}

E. coli cells from freshly transformed plates were inoculated in $20 \mathrm{ml}$ expression media. In order to produce high density expression cultures with tight regulation of induction and expression in shake flasks we designed a complex media inspired from the principle of Studier's autoinduction media (Studier, 2005). We use adequate amount of glucose to prevent the unintended induction and leaky expression of target protein as well as phosphate buffer to prevent acidity as a result of glucose metabolism from the excessive glucose in the media. In addition, the medium contained glycerol, nitrogen, sulphur, and magnesium for promoting high density growth. Unlike the studier's autoinduction media our media lack lactose therefore expression can be induced with IPTG and expressed at required temperature (Studier, 2005; 1.6

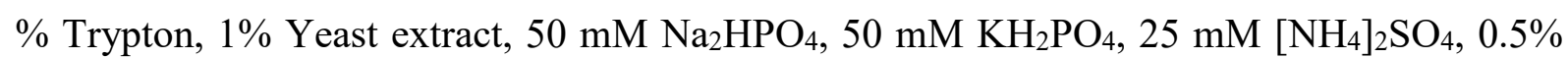
Glycerol, $0.5 \%$ Glucose, $\left.2 \mathrm{mM} \mathrm{MgSO}_{4}\right)$ with ampicillin $(100 \mathrm{mg} / \mathrm{ml})$ and chloramphenicol (34 $\mathrm{mg} / \mathrm{ml})$ or kanamycin $(200 \mathrm{mg} / \mathrm{ml})$ and chloramphenicol $(34 \mathrm{mg} / \mathrm{ml})$ and grown overnight (16 hours) at $37{ }^{\circ} \mathrm{C}, 200 \mathrm{rpm}$. Note, high concentration of kanamycin was used to prevent the unintended resistance promoted by high phosphate concentration (Studier, 2005). Supernatant from the overnight culture was removed by centrifugation at $4{ }^{\circ} \mathrm{C}, 5000 \mathrm{~g}$ for 2 minutes. Cells were resuspended in fresh media with a starting $\mathrm{OD}_{600}$ of 0.1 and grown at $37^{\circ} \mathrm{C}, 200 \mathrm{rpm}$ for about 2 hours 30 minutes until the $\mathrm{OD}_{600}=1$. Protein expression was induced at $28{ }^{\circ} \mathrm{C}, 200$ $\mathrm{rpm}$, for 4 hours by addition of $1 \mathrm{mM}$ IPTG, and harvested by centrifugation at $4^{\circ} \mathrm{C}, 6,000 \mathrm{~g}$ for 5 minutes. Protein purification was performed as per the previous report (Abts et al., 2013). Hexa-histidine tagged protein was purified using Nickle-based affinity chromatography (HisTrap HP GE healthcare) on Akta prime FPLC system. Cells were thawed on ice and resuspended in buffer A (20 mM HEPES pH 8.0, $200 \mathrm{mM} \mathrm{NaCl}, 1 \mathrm{mM}$ EDTA, $10 \mathrm{mM}$ Imidazole $\mathrm{pH}$ 8.0; $1 \mathrm{mM}$ PMSF, $0.5 \mathrm{mg} / \mathrm{ml}$ Lysozyme, $0.5 \mathrm{mg} / \mathrm{ml}$ DNase, $1 \mathrm{mM} \beta$ mercaptoethanol $[\beta-\mathrm{ME}])$. Subsequently, cells were lysed by sonication on ice and centrifuged at $4{ }^{\circ} \mathrm{C} 18,000 \mathrm{~g}$ for 30 minutes. Resulting supernatant was loaded on to a pre-equilibrated column with buffer B (20 mM HEPES pH 8.0, $200 \mathrm{mM} \mathrm{NaCl,10} \mathrm{mM} \mathrm{Imidazole),} \mathrm{washed} \mathrm{with}$ buffer C (20 mM HEPES pH 8.0, $200 \mathrm{mM} \mathrm{NaCl}, 50 \mathrm{mM}$ Imidazole, $1 \mathrm{mM} \beta$-ME), eluted with buffer D (20 mM HEPES pH 8.0, $200 \mathrm{mM} \mathrm{NaCl}, 300 \mathrm{mM}$ Imidazole, 1mM $\beta$-ME) and further 
Devan, Schott-Verdugo et al.

482

483

484

485

486

487

488

489

490

491

492

493

494

495

496

497

498

499

500

501

502

503

504

505

506

507

508

509

510

511

purified by Size Exclusion Chromatography (HiLoad 26/600 Superdex 200, GE healthcare), pre-equilibrated with buffer E (20 mM HEPES pH 8.0, $200 \mathrm{mM} \mathrm{NaCl,} 1 \mathrm{mM} \beta$-ME). For crystallization studies, H-Rrm4-NT4 was purified as above except that the buffers were prepared with high salt $(500 \mathrm{mM} \mathrm{NaCl})$ and without $\beta$-ME.

GST-tagged protein was purified using Glutathione-based affinity chromatography (GSTrap FF GE healthcare). Cells were thawed on ice and resuspend in Buffer F (20 mM HEPES pH 8.0, $200 \mathrm{mM} \mathrm{NaCl}, 1 \mathrm{mM}$ EDTA, pH 8.0; 1 mM PMSF, $0.1 \mathrm{mg} / \mathrm{ml}$ Lysozyme, $1 \mathrm{mM} \beta$-ME). Subsequently, cells were lysed by sonication on ice and centrifuged at $4{ }^{\circ} \mathrm{C}, 18,000 \mathrm{~g}$ for 30 minutes. The resulting supernatant was loaded onto a pre-equilibrated column with buffer E (20 mM HEPES pH 8.0, $200 \mathrm{mM} \mathrm{NaCl}, 1 \mathrm{mM} \beta$-ME) and washed with the same buffer, eluted with buffer H (20 mM HEPES pH 8.0, $200 \mathrm{mM} \mathrm{NaCl}, 10 \mathrm{mM}$ reduced glutathione, $1 \mathrm{mM} \beta$ ME), and further purified by size exclusion chromatography (HiLoad 16/600 Superdex 200 GE healthcare), pre-equilibrated with buffer E. Protein purity was analysed on SDS PAGE. All the purified proteins were concentrated, centrifuged at $4^{\circ} \mathrm{C}, 100,000 \mathrm{~g}$ for 30 minutes, quantified by Nanodrop A280, aliquoted, and stored at $-80^{\circ} \mathrm{C}$. Peptides for ITC experiments were customsynthesised and purchased from Genscript, USA (see Fig. 3A for peptide sequence).

\section{GST pull-down experiments}

Pull-down assays were performed as per the previous report (Jankowski et al., 2019). GSTMLLE variants and HS-PAM2 variants were expressed in E. coli and harvested as described above. Cell pellets from $50 \mathrm{ml} \mathrm{E}$. coli expression culture were resuspended in $10 \mathrm{ml}$ buffer $\mathrm{F}$ (20 mM HEPES pH 8.0, 200 mM NaCl, 1 mM EDTA; 0.5\% Nonidet P-40, 1 mM PMSF, 0.1 $\mathrm{mg} / \mathrm{ml}$ Lysozyme). Cells were lysed by sonication on ice and centrifuged at $4{ }^{\circ} \mathrm{C}, 16,000 \mathrm{~g}$ for 10 minutes. $1 \mathrm{~mL}$ of the resulting supernatant was incubated for 1 hour at $4^{\circ} \mathrm{C}$ on constant agitation of 1,000 rpm with $100 \mu \mathrm{L}$ glutathione sepharose (GS) resin (GE healthcare), preequilibrated in buffer F. The GS resin was washed three times with $1 \mathrm{ml}$ of buffer $\mathrm{G}(20 \mathrm{mM}$ HEPES pH 8.0, 200 mM NaCl, 1 mM EDTA, $0.5 \%$ Nonidet P-40). Subsequently, supernatant of HS-PAM2 variants was added to the GST-MLLE variant bound resins and incubated for 1 hour at $4{ }^{\circ} \mathrm{C}$ on agitation. The resins were washed as aforementioned and resuspended in 100 $\mu \mathrm{L}$ of $2 \mathrm{x}$ Laemmli loading buffer and boiled for 10 minutes at $95^{\circ} \mathrm{C}$ and analysed by western blotting. 
Devan, Schott-Verdugo et al.

\section{SDS-PAGE and immunoblotting}

513 All SDS-PAGE and Western blotting experiments were performed as per the previous report.

514 (Jankowski et al., 2019). For Western blotting, protein samples were resolved by 12 \% SDS-

515 PAGE and transferred to a PVDF membrane (GE Healthcare) by semi-dry blotting. Western

516 blot analysis was performed with anti-His (Sigma H1029). Anti-mouse IgG HRP conjugate

517 (Promega W4021) was used as a secondary antibody. The activity was detected using the

518 AceGlow blotting detection system (VWR Peqlab, Erlangen, Germany).

\section{Multiangle laser light scattering (MALS)}

520 MALS was performed as per the previous report (Weiler et al., 2021). Superdex 200 Increase 521 10/300 GL column (GE Healthcare) was pre-equilibrated overnight at a flow rate of $5220.1 \mathrm{ml} /$ minute with buffer E (20 mM HEPES pH 8.0, $200 \mathrm{mM} \mathrm{NaCl}, 1 \mathrm{mM} \beta-\mathrm{ME})$. For each 523 analysis, $200 \mu 1$ of protein sample at the concentrations of $2.0 \mathrm{mg} / \mathrm{ml}$ was loaded onto the 524 column at the flow rate of $0.6 \mathrm{ml} /$ minute using 1260 binary pump (Agilent Technologies). 525 Scattered light was measured with miniDAWN TREOS II light scatterer, (Wyatt Technologies), 526 and the refractive index was measured with Optilab T-rEX refractometer, (Wyatt 527 Technologies). Data analysis was performed with the software ASTRA 7.3.2.21 (Wyatt 528 Technologies; Slotboom et al., 2008).

\section{Crystallization of H-Rrm4 NT4}

530 Initial crystallization conditions were searched using MRC 3 96-well sitting drop plates and 531 various commercially available crystallization screens at $12{ }^{\circ} \mathrm{C} .0 .1 \mu 1$ homogeneous protein solution $(10 \mathrm{mg} / \mathrm{ml}$ in $20 \mathrm{mM}$ Hepes $\mathrm{pH} 8.0,500 \mathrm{mM} \mathrm{NaCl})$ was mixed with $0.1 \mu 1$ reservoir solution and equilibrated against $40 \mu \mathrm{l}$ of the reservoir. After one week, initial rod-shaped crystals were found, which were then further optimized by slightly varying the precipitant concentrations. Optimisation was also performed in sitting drop plates (24-well) at $12{ }^{\circ} \mathrm{C}$ but

536 by mixing $1 \mu 1$ protein solution with $1 \mu 1$ of the reservoir solution, equilibrated against $300 \mu 1$ 537 reservoir solution. Best diffracting crystals were grown within 7 days in $0.1 \mathrm{M}$ Hepes $\mathrm{pH}$ 7.5, $53820 \%(w / v)$ PEG 10000 (Qiagen PEG I, D5). Crystal-containing drops were overlaid with $2 \mu 1$ mineral oil before harvesting the crystal and immediately flash-frozen in liquid nitrogen.

\section{Data collection, processing, and structure refinement}

541 A complete data set of the H-Rrm4-NT4 were collected at beamline ID23EH1 (ESRF, France) 542 at $100 \mathrm{~K}$ and wavelength $0.98 \AA$ up to $2.6 \AA$ resolution. All data were processed using the 
Devan, Schott-Verdugo et al.

automated pipeline at the EMBL HAMBURG and reprocessed afterwards using XDS (Kabsch, 2014). The above obtained model for MLLE2 by TopModel was successfully used to phase the $2.6 \AA$ data set of Rrm4 MLLE using the program Phaser from the program suite Phenix (Afonine et al., 2012). The structure was then refined in iterative cycles of manual building and refinement in coot (Emsley \& Cowtan, 2004) followed by software-based refinements using the program suite Phenix (Afonine et al., 2012.) All residues were in the preferred and additionally allowed regions of the Ramachandran plot (Appendix Table S2). The data collection and refinement statistics are listed in Appendix Table S2. The comparison of the structure and models were performed using the superpose tool of PHENIX calculating the corresponding RMSD. The images of the models were prepared using PyMOL. The structure was deposited at the worldwide protein data bank under the accession code 7PZE.

\section{Small angle $\mathrm{X}$-ray scattering}

We collected all SAXS data on beamline BM29 at the ESRF Grenoble (Franke et al., 2017 Pernot et al., 2013; Pernot et al., 2010). The beamline was equipped with a PILATUS 2M detector (Dectris) with a fixed sample to distance of $2.827 \mathrm{~m}$. To prevent concentrationdependent oligomerization, we performed the measurements with concentrations of $0.6 \mathrm{mg} / \mathrm{ml}$ at a temperature of $10^{\circ} \mathrm{C}$ in buffer E. We collected one frame each second and scaled the data to absolute intensity against water. All used programs for data processing were part of the ATSAS Software package (Version 3.0.3; Manalastas-Cantos et al., 2021). The primary data reduction was performed with the program Primus (Konarev et al., 2003). With Primus and the included Guinier approximation (Franke \& Svergun, 2009), we determined the forward scattering $I(0)$ and the radius of gyration $\left(R_{g}\right)$. The pair-distribution function $p(r)$ was calculated with Gnom (Svergun, 1992) and was used to estimate the maximum particle dimension $\left(D_{\max }\right)$. Due to the high flexibility of the proteins we performed an Ensemble Optimization Method (EOM; Tria et al., 2015; default parameters, 10,000 models in initial ensemble, native-like models, constant subtraction allowed) with the predicted MLLE domains from TopModel (Mulnaes et al., 2021; Mulnaes et al., 2020b) for H-Rrm4-NT4 and G-Rrm4 with an additional GST (PDB1ua5). We uploaded the data to the Small Angle Scattering Biological Data Bank (SASBDB; Kikhney et al., 2020; Valentini et al., 2015) with the accession codes SASDMS5(GRrm4) and SASDMT5 (H-Rrm4-NT4). 
Devan, Schott-Verdugo et al.

573

574

575

576

577

578

579

580

581

582

583

584

585

586

587

588

589

590

591

592

593

594

595

596

597

598

599

600

601

602

603

\section{Isothermal titration calorimetry}

All ITC experiments were performed as per the previous report (Abts et al., 2013). All the protein samples used in ITC were centrifuged at 451,000 g for 30 minutes and quantified by Nanodrop (A280) before use. The concentration of GST-MLLE variants was adjusted to $30 \mu \mathrm{M}$ and PAM2 peptide variants was adjusted to $300 \mu \mathrm{M}$ using buffer G (20 mM HEPES pH 8.0, $200 \mathrm{mM} \mathrm{NaCl}, 1 \mathrm{mM} 2 \mathrm{ME}$ ) at $25^{\circ} \mathrm{C}$.Using an MicroCal iTC200 titration calorimeter (Malvern Panalytical technologies), a PAM2 peptide variant with a volume of $40 \mu \mathrm{L}$ was titrated to the different GST-MLLE variants. All experiments were repeated at least twice. ITC measurements were performed at $25^{\circ} \mathrm{C}$ with 40 injections $(1 \mu \mathrm{L}$ each). Only the first injection had a volume of $0.5 \mu \mathrm{L}$ and was discarded from the isotherm. The other technical parameters were reference power, $5 \mu \mathrm{cal} \mathrm{s}^{-1}$; stirring speed, $1000 \mathrm{rpm}$; spacing time, $120 \mathrm{~s}$, and a filter period, $5 \mathrm{~s}$. The resulting isotherm was fitted with a one-site binding model using MicroCal Origin for ITC software (MicroCal LLC).

\section{Microscopy, image processing and image analysis}

Laser-based epifluorescence-microscopy was performed on a Zeiss Axio Observer.Z1 as previously described (Jankowski et al., 2019). Co-localisation studies of dynamic processes were carried out with a two-channel imager (DV2, Photometrics, Tucson, AZ, USA; Baumann et al., 2016). To quantify uni- and bipolar hyphal growth, cells were grown in $30 \mathrm{ml}$ cultures to an $\mathrm{OD}_{600}$ of 0.5 , and hyphal growth was induced. After 6 hours, more than 100 hyphae were analysed per strains towards their growth behaviour $(n=3)$. Cells were assessed for unipolar and bipolar growth as well as the formation of a basal septum. To analyse the signal number, velocity, and travelled distance of fluorescently labelled proteins, movies with an exposure time of $150 \mathrm{~ms}$ and 150 frames were recorded. More than 25 hyphae were analysed per strain $(\mathrm{n}=$ 3). All movies and images were possessed and analysed using the Metamorph software (Version 7.7.0.0, Molecular Devices, Seattle, IL, USA). For the generation of kymographs, $20 \mu \mathrm{m}$ of hyphal cell starting at the hyphal tip were used. For statistical analysis of signal number, velocity, and travelled distance, processive signals with a travelled distance of more than $5 \mu \mathrm{m}$ were conducted and counted manually. Data points represent means from three independent experiments $(n=3)$ with mean of means (red line) and SEM. For all statistical evaluations, twotailed Student's $t$-tests were used. 
Devan, Schott-Verdugo et al.

604

605

606

607

608

609

610

611

612

613

614

615

616

617

618

619

620

621

622

623

624

625

626

627

628

629

630

631

632

633

\section{Acknowledgements}

We thank Drs. Florian Altegoer and Dierk Niessing as well as laboratory members for critical reading of the manuscript. We acknowledge Drs. Georg Groth, Alexander Minges, and Mohan Gopalswamy for support with ITC experiments. We gratefully acknowledge the computational support provided by the "Center for Information and Media Technology" (ZIM) at the Heinrich Heine University Düsseldorf and the computing time provided by the John von Neumann Institute for Computing (NIC) on the supercomputer JUWELS at Jülich Supercomputing Centre (JSC) (user IDs: HKF7, VSK33). The synchrotron MX data were collected at ESRF ID23-EH1. We thank Sylvain Engilberge for the assistance in using the beamline. The final SAXS experiments were performed on beamline BM29 at the European Synchrotron Radiation Facility (ESRF), Grenoble, France. We are grateful to Dihia Moussaoui at the ESRF for providing assistance during data collection. The work was funded by grants from the Deutsche Forschungsgemeinschaft under Germany's Excellence Strategy EXC-2048/1 - Project ID 39068111 to MF; Project-ID 267205415 - SFB 1208 to MF (project A09), HG (project A03), and LS (project A01). The Center for Structural Studies is funded by the Deutsche Forschungsgemeinschaft (DFG Grant number 417919780; INST 208/740-1 FUGG; INST 208/761-1 FUGG).

\section{Author contributions}

SKD, SSV, LS, SHJS, HG, and MF designed this study and analysed the data. SKD and SSV contributed equally to the structural biology of the MLLE binding platform; SKD performed the wet lab experiments and SSV was responsible for modelling. KM and SKD performed the cell biological experiments. LB coordinated strain generation and experimental design. JR, EH, AH contributed to SAXS, MALS, and X ray analysis, respectively. SKD, SSV, LS, SHJS, HG, and MF drafted and revised the manuscript with input from all co-authors. SKD, SSV, SHJS, $\mathrm{HG}$ and MF directed the project.

\section{Conflict of interest}

The authors declare that they have no competing interests. 
Devan, Schott-Verdugo et al.

\section{References}

Abts A, Montalban-Lopez M, Kuipers OP, Smits SH, Schmitt L (2013) NisC binds the FxLx motif of the nisin leader peptide. Biochemistry 52: 5387-5395

Afonine PV, Grosse-Kunstleve RW, Echols N, Headd JJ, Moriarty NW, Mustyakimov M, Terwilliger TC, Urzhumtsev A, Zwart PH, Adams PD (2012) Towards automated crystallographic structure refinement with phenix.refine. Acta Crystallogr D Biol Crystallogr 68: 352-367

Albrecht M, Lengauer T (2004) Survey on the PABC recognition motif PAM2. Biochem Biophys Res Commun 316: 129-138

Baek M, DiMaio F, Anishchenko I, Dauparas J, Ovchinnikov S, Lee GR, Wang J, Cong Q, Kinch LN, Schaeffer RD et al. (2021) Accurate prediction of protein structures and interactions using a three-track neural network. Science 373: 871-876

Baumann S, König J, Koepke J, Feldbrügge M (2014) Endosomal transport of septin mRNA and protein indicates local translation on endosomes and is required for correct septin filamentation. $E M B O$ Rep 15: 94-102

Baumann S, Pohlmann T, Jungbluth M, Brachmann A, Feldbrügge M (2012) Kinesin-3 and dynein mediate microtubule-dependent co-transport of mRNPs and endosomes. J Cell Sci 125: $2740-2752$

Baumann S, Zander S, Weidtkamp-Peters S, Feldbrügge M (2016) Live cell imaging of septin dynamics in Ustilago maydis. In: Methods in Cell Biol: Septins, Gladfelter A.S. (ed.) pp. 143-159. Elsevier Inc.:

Becht P, König J, Feldbrügge M (2006) The RNA-binding protein Rrm4 is essential for polarity in Ustilago maydis and shuttles along microtubules. J Cell Sci 119: 4964-4973

Béthune J, Jansen RP, Feldbrügge M, Zarnack K (2019) Membrane-associated RNA-binding proteins orchestrate organelle-coupled translation Trends in cell biology 29: 178-188

Brachmann A, König J, Julius C, Feldbrügge M (2004) A reverse genetic approach for generating gene replacement mutants in Ustilago maydis. Mol Gen Genom 272: 216-226

Brachmann A, Weinzierl G, Kämper J, Kahmann R (2001) Identification of genes in the bW/bE regulatory cascade in Ustilago maydis. Mol Microbiol 42: 1047-1063

Cioni JM, Lin JQ, Holtermann AV, Koppers M, Jakobs MAH, Azizi A, Turner-Bridger B, Shigeoka T, Franze K, Harris WA et al. (2019) Late endosomes act as mRNA translation platforms and sustain mitochondria in axons. Cell 176: 56-72 e15

Das S, Vera M, Gandin V, Singer RH, Tutucci E (2021) Intracellular mRNA transport and localized translation. Nat Rev Mol Cell Biol 22: 483-504 
Devan, Schott-Verdugo et al.

668

669

670

671

672

673

674

675

676

677

678

679

680

681

682

683

684

685

686

687

688

689

690

691

692

693

694

695

696

697

698

699

700

701

Deo RC, Sonenberg N, Burley SK (2001) X-ray structure of the human hyperplastic discs protein: an ortholog of the C-terminal domain of poly(A)-binding protein. Proc Natl Acad Sci U S A 98: 4414-4419

Emsley P, Cowtan K (2004) Coot: model-building tools for molecular graphics. Acta Crystallogr D Biol Crystallogr 60: 2126-2132

Fernandopulle MS, Lippincott-Schwartz J, Ward ME (2021) RNA transport and local translation in neurodevelopmental and neurodegenerative disease. Nature neuroscience

Franke D, Petoukhov MV, Konarev PV, Panjkovich A, Tuukkanen A, Mertens HDT, Kikhney AG, Hajizadeh NR, Franklin JM, Jeffries CM et al. (2017) ATSAS 2.8: a comprehensive data analysis suite for small-angle scattering from macromolecular solutions. J Appl Crystallogr 50: 1212-1225

Franke D, Svergun DI (2009) DAMMIF, a program for rapid ab-initio shape determination in small-angle scattering. J Appl Crystallogr 42: 342-346

Grimm C, Pelz JP, Schneider C, Schaffler K, Fischer U (2020) Crystal structure of a variant PAM2 motif of LARP4B bound to the MLLE domain of PABPC1. Biomol 10

Haag C, Steuten B, Feldbrügge M (2015) Membrane-coupled mRNA trafficking in fungi. Annu Rev Microbiol 69: 265-281

Jankowski S, Pohlmann T, Baumann S, Müntjes KM, Devan SK, Zander S, Feldbrügge M (2019) The multi PAM2 protein Upa2 functions as novel core component of endosomal mRNA transport. EMBO Rep 24: e47381

Jinek M, Fabian MR, Coyle SM, Sonenberg N, Doudna JA (2010) Structural insights into the human GW182-PABC interaction in microRNA-mediated deadenylation. Nat Struct Mol Biol 17: 238-240

Jumper J, Evans R, Pritzel A, Green T, Figurnov M, Ronneberger O, Tunyasuvunakool K, Bates R, Zidek A, Potapenko A et al. (2021) Highly accurate protein structure prediction with AlphaFold. Nature 596: 583-589

Kabsch W (2014) Processing of X-ray snapshots from crystals in random orientations. Acta Crystallogr D Biol Crystallogr 70: 2204-2216

Kikhney AG, Borges CR, Molodenskiy DS, Jeffries CM, Svergun DI (2020) SASBDB: Towards an automatically curated and validated repository for biological scattering data. Protein Sci 29: 66-75

Konarev PV, Volkov VV, Sokolova AV, Koch MHJ, Svergun DI (2003) PRIMUS: a Windows PC-based system for small-angle scattering data analysis. J Appl Crystallogr 36: 12771282 
bioRxiv preprint doi: $h$ ttps://doi.org/10.1101/2021.10.25.465676; this version posted October 25, 2021. The copyright holder for this preprint (which was not certified by peer review) is the author/funder, who has granted bioRxiv a license to display the preprint in perpetuity. It is made available under aCC-BY-NC 4.0 International license.

Devan, Schott-Verdugo et al.

Kozlov G, De Crescenzo G, Lim NS, Siddiqui N, Fantus D, Kahvejian A, Trempe JF, Elias D, Ekiel I, Sonenberg N et al. (2004) Structural basis of ligand recognition by PABC, a highly specific peptide-binding domain found in poly(A)-binding protein and a HECT ubiquitin ligase. EMBO J 23: 272-281

Kozlov G, Gehring K (2010) Molecular basis of eRF3 recognition by the MLLE domain of poly(A)-binding protein. PLoS One 5: e10169

Kozlov G, Menade M, Rosenauer A, Nguyen L, Gehring K (2010) Molecular determinants of PAM2 recognition by the MLLE domain of poly(A)-binding protein. J Mol Biol 397: 397407

Kozlov G, Trempe JF, Khaleghpour K, Kahvejian A, Ekiel I, Gehring K (2001) Structure and function of the C-terminal PABC domain of human poly(A)-binding protein. Proc Natl Acad Sci U S A 98: 4409-4413

Liao YC, Fernandopulle MS, Wang G, Choi H, Hao L, Drerup CM, Patel R, Qamar S, NixonAbell J, Shen Y et al. (2019) RNA granules hitchhike on lysosomes for long-distance transport, using annexin A11 as a molecular tether. Cell 179: 147-164 e120

Lim NS, Kozlov G, Chang TC, Groover O, Siddiqui N, Volpon L, De Crescenzo G, Shyu AB, Gehring K (2006) Comparative peptide binding studies of the PABC domains from the ubiquitin-protein isopeptide ligase HYD and poly(A)-binding protein. Implications for HYD function. The Journal of biological chemistry 281: 14376-14382

Loubradou G, Brachmann A, Feldbrügge M, Kahmann R (2001) A homologue of the transcriptional repressor Ssn6p antagonizes cAMP signalling in Ustilago maydis. Mol Microbiol 40: 719-730

Manalastas-Cantos K, Konarev PV, Hajizadeh NR, Kikhney AG, Petoukhov MV, Molodenskiy DS, Panjkovich A, Mertens HDT, Gruzinov A, Borges C et al. (2021) ATSAS 3.0: expanded functionality and new tools for small-angle scattering data analysis. $J$ Appl Crystallogr 54

Mangus DA, Amrani N, Jacobson A (1998) Pbplp, a factor interacting with Saccharomyces cerevisiae poly(A)-binding protein, regulates polyadenylation. Molecular and cellular biology 18: 7383-7396

Mangus DA, Evans MC, Jacobson A (2003) Poly(A)-binding proteins: multifunctional scaffolds for the post-transcriptional control of gene expression. Genome Biol 4: 223

Mattijssen S, Kozlov G, Fonseca BD, Gehring K, Maraia RJ (2021) LARP1 and LARP4: up close with PABP for mRNA 3' poly(A) protection and stabilization. RNA Biol 18: 259-274 Mofatteh M, Bullock SL (2017) SnapShot: Subcellular mRNA localization. Cell 169: 178.e171 
bioRxiv preprint doi: $\mathrm{https}$ //doi.org/10.1101/2021.10.25.465676; this version posted October 25, 2021. The copyright holder for this preprint (which was not certified by peer review) is the author/funder, who has granted bioRxiv a license to display the preprint in perpetuity. It is made available under aCC-BY-NC 4.0 International license.

Devan, Schott-Verdugo et al.

Müller J, Pohlmann T, Feldbrügge M (2019) Core components of endosomal mRNA transport are evolutionarily conserved in fungi. Fungal Genet Biol 126: 12-16

Mulnaes D, Gohlke H (2018) TopScore: using deep neural networks and large diverse data sets for accurate protein model quality assessment. J Chem Theory Comput 14: 6117-6126

Mulnaes D, Koenig F, Gohlke H (2021) TopSuite Web Server: A Meta-Suite for DeepLearning-Based Protein Structure and Quality Prediction. Journal of chemical information and modeling 61: 548-553

Mulnaes D, Porta N, Clemens R, Apanasenko I, Reiners J, Gremer L, Neudecker P, Smits SHJ, Gohlke H (2020a) TopModel: template-based protein structure prediction at low sequence identity using top-down consensus and deep neural networks. J Chem Theory Comput 16: 1953-1967

Mulnaes D, Porta N, Clemens R, Apanasenko I, Reiners J, Gremer L, Neudecker P, Smits SHJ, Gohlke H (2020b) TopModel: Template-Based Protein Structure Prediction at Low Sequence Identity Using Top-Down Consensus and Deep Neural Networks. $J$ Chem Theory Comput 16: 1953-1967

Munoz-Escobar J, Matta-Camacho E, Kozlov G, Gehring K (2015) The MLLE domain of the ubiquitin ligase UBR5 binds to its catalytic domain to regulate substrate binding. The Journal of biological chemistry 290: 22841-22850

Müntjes K, Devan SK, Reichert AS, Feldbrügge M (2021) Linking transport and translation of $\mathrm{mRNAs}$ with endosomes and mitochondria. EMBO reports accepted for publication

Müntjes K, Philipp M, Husemann L, Heucken N, Weidtkamp-Peters S, Schipper K, Zurbriggen MD, Feldbrügge M (2020) Establishing polycistronic expression in the model microorganism Ustilago maydis. Front Microbiol 11: 1384

Niessing D, Jansen RP, Pohlmann T, Feldbrügge M (2018) mRNA transport in fungal top models. Wiley interdisciplinary reviews RNA 9: e1453

Olgeiser L, Haag C, Boerner S, Ule J, Busch A, Koepke J, König J, Feldbrügge M, Zarnack K (2019) The key protein of endosomal mRNP transport Rrm4 binds translational landmark sites of cargo mRNAs. EMBO Rep 20: e46588

Pernot P, Round A, Barrett R, De Maria Antolinos A, Gobbo A, Gordon E, Huet J, Kieffer J, Lentini M, Mattenet M et al. (2013) Upgraded ESRF BM29 beamline for SAXS on macromolecules in solution. Journal of synchrotron radiation 20: 660-664

Pernot P, Theveneau P, Giraud T, Fernandes RN, Nurizzo D, Spruce D, Surr J, McSweeney S, Round A, Felisaz F et al. (2010) New beamline dedicated to solution scattering from 
bioRxiv preprint doi: https//doi.org/10.1101/2021.10 25.465676; this version posted October 25, 2021. The copyright holder for this preprint (which was not certified by peer review) is the author/funder, who has granted bioRxiv a license to display the preprint in perpetuity. It is made available under aCC-BY-NC 4.0 International license.

Devan, Schott-Verdugo et al.

biological macromolecules at the ESRF. Journal of Physics: Conference Series 247: 012009

Pohlmann T, Baumann S, Haag C, Albrecht M, Feldbrügge M (2015) A FYVE zinc finger domain protein specifically links mRNA transport to endosome trafficking. eLife 4: e06041

Quentin D, Schuhmacher JS, Klink BU, Lauer J, Shaikh TR, Huis in t't Veld PJ, Welp LM, Urlaub H, Zerial M, Raunser S (2021) Structure of the human FERRY Rab5 effector complex. bioRiv 10.1101/2021.06.21.449265

Sawazaki R, Imai S, Yokogawa M, Hosoda N, Hoshino SI, Mio M, Mio K, Shimada I, Osawa M (2018) Characterization of the multimeric structure of poly(A)-binding protein on a poly(A) tail. Sci Rep 8: 1455

Schäfer IB, Yamashita M, Schuller JM, Schussler S, Reichelt P, Strauss M, Conti E (2019) Molecular bsis for poly(A) RNP architecture and recognition by the Pan2-Pan3 deadenylase. Cell 177: 1619-1631 e1621

Schuhmacher JS, Dieck ST, Christoforidis S, Landerer C, Hersemann L, Seifert S, Giner A, Toth-Petroczy A, Kalaidzidis Y, Schumann EM et al. (2021) The novel Rab5 effector FERRY links early endosomes with the translation machinery. BioRiv 10.1101/2021.06.20.449167

Slotboom DJ, Duurkens RH, Olieman K, Erkens GB (2008) Static light scattering to characterize membrane proteins in detergent solution. Methods 46: 73-82

Stenmark H, Aasland R, Driscoll PC (2002) The phosphatidylinositol 3-phosphate-binding FYVE finger. FEBS Lett 513: 77-84

Studier FW (2005) Protein production by auto-induction in high density shaking cultures. Protein Expr Purif 41: 207-234

Su H, Meng S, Lu Y, Trombly MI, Chen J, Lin C, Turk A, Wang X (2011) Mammalian hyperplastic discs homolog EDD regulates miRNA-mediated gene silencing. Mol Cell 43: 97-109

Svergun DI (1992) Determination of the regularization parameter in indirect-transform methods using perceptual criteria. . J Appl Crystallogr 25: 495-503

Terfrüchte M, Joehnk B, Fajardo-Somera R, Braus G, Riquelme M, Schipper K, Feldbrügge M (2014) Establishing a versatile Golden Gate cloning system for genetic engineering in fungi. Fungal Genet Biol 62: 1-10

Tian L, Chou HL, Fukuda M, Kumamaru T, Okita TW (2020a) mRNA localization in plant cells. Plant Physiol 182: 97-109 
Devan, Schott-Verdugo et al.

Tian L, Chou HL, Zhang L, Hwang SK, Starkenburg SR, Doroshenk KA, Kumamaru T, Okita TW (2018) RNA-binding protein RBP-P is required for glutelin and prolamine mRNA localization in rice endosperm cells. Plant Cell 30: 2529-2552

Tian L, Doroshenk KA, Zhang L, Fukuda M, Washida H, Kumamaru T, Okita T (2020b) Zipcode RNA-binding proteins and membrane trafficking proteins cooperate to transport glutelin mRNAs in rice endosperm. Plant Cell 32: 2566-2581

Tria G, Mertens HD, Kachala M, Svergun DI (2015) Advanced ensemble modelling of flexible macromolecules using X-ray solution scattering. IUCrJ 2: 207-217

Valentini E, Kikhney AG, Previtali G, Jeffries CM, Svergun DI (2015) SASBDB, a repository for biological small-angle scattering data. Nucleic Acids Res 43: D357-363

Weiler AJ, Spitz O, Gudzuhn M, Schott-Verdugo SN, Kamel M, Thiele B, Streit RW, Kedrov A, L. S, Gohlke H et al. (2021) Novel intracellular phospholipase B from Pseudomonas aeruginosa with activity towards endogenous phospholipids affects biofilm assembly. bioRiv doi.org/10.1101/2021.06.15.448513

Xie J, Kozlov G, Gehring K (2014) The "tale" of poly(A) binding protein: the MLLE domain and PAM2-containing proteins. Biochim Biophys Acta 1839: 1062-1068

Yang R, Gaidamakov SA, Xie J, Lee J, Martino L, Kozlov G, Crawford AK, Russo AN, Conte MR, Gehring K et al. (2011) La-related protein 4 binds poly(A), interacts with the poly(A)binding protein MLLE domain via a variant PAM2w motif, and can promote mRNA stability. Mol Cell Biol 31: 542-556

Zander S, Baumann S, Weidtkamp-Peters S, Feldbrügge M (2016) Endosomal assembly and transport of heteromeric septin complexes promote septin cytoskeleton formation. $J$ Cell Sci 129: 2778-2792 
bioRxiv preprint doi: $h$ ttps://doi.org/10.1101/2021.10.25.465676; this version posted October 25, 2021. The copyright holder for this preprint (which was not certified by peer review) is the author/funder, who has granted bioRxiv a license to display the preprint in perpetuity. It is made available under aCC-BY-NC 4.0 International license.

Devan, Schott-Verdugo et al.

A

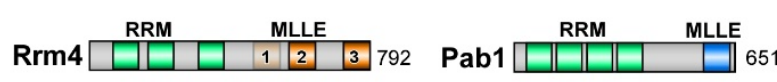

Upa1 PAM2 PL1 5XANK

B

HsPABPC

TAPABPC1

TCPABPC1

LMPABPC1

SCPABPC1

HSUBR5

RnUBR5

UmPab1

UmRrm 4-MLLE3

UmRrm4-MLLE2

UmRrm4-MLLE1

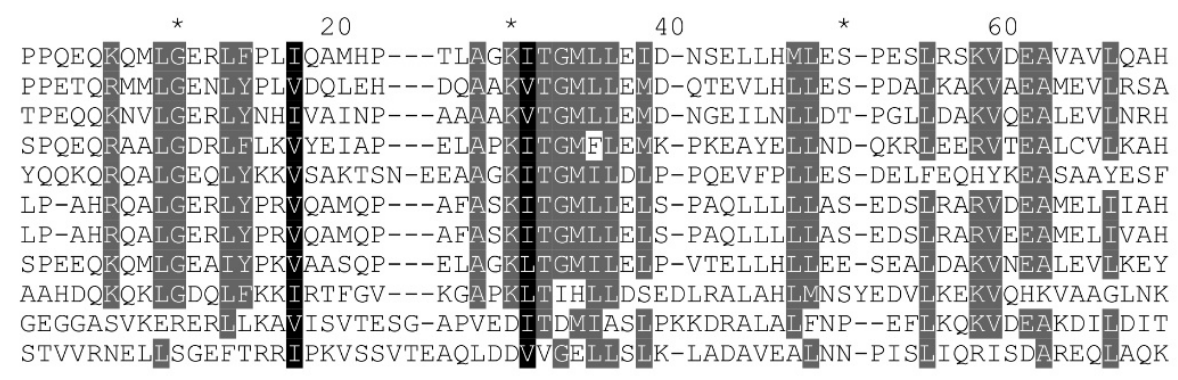

C

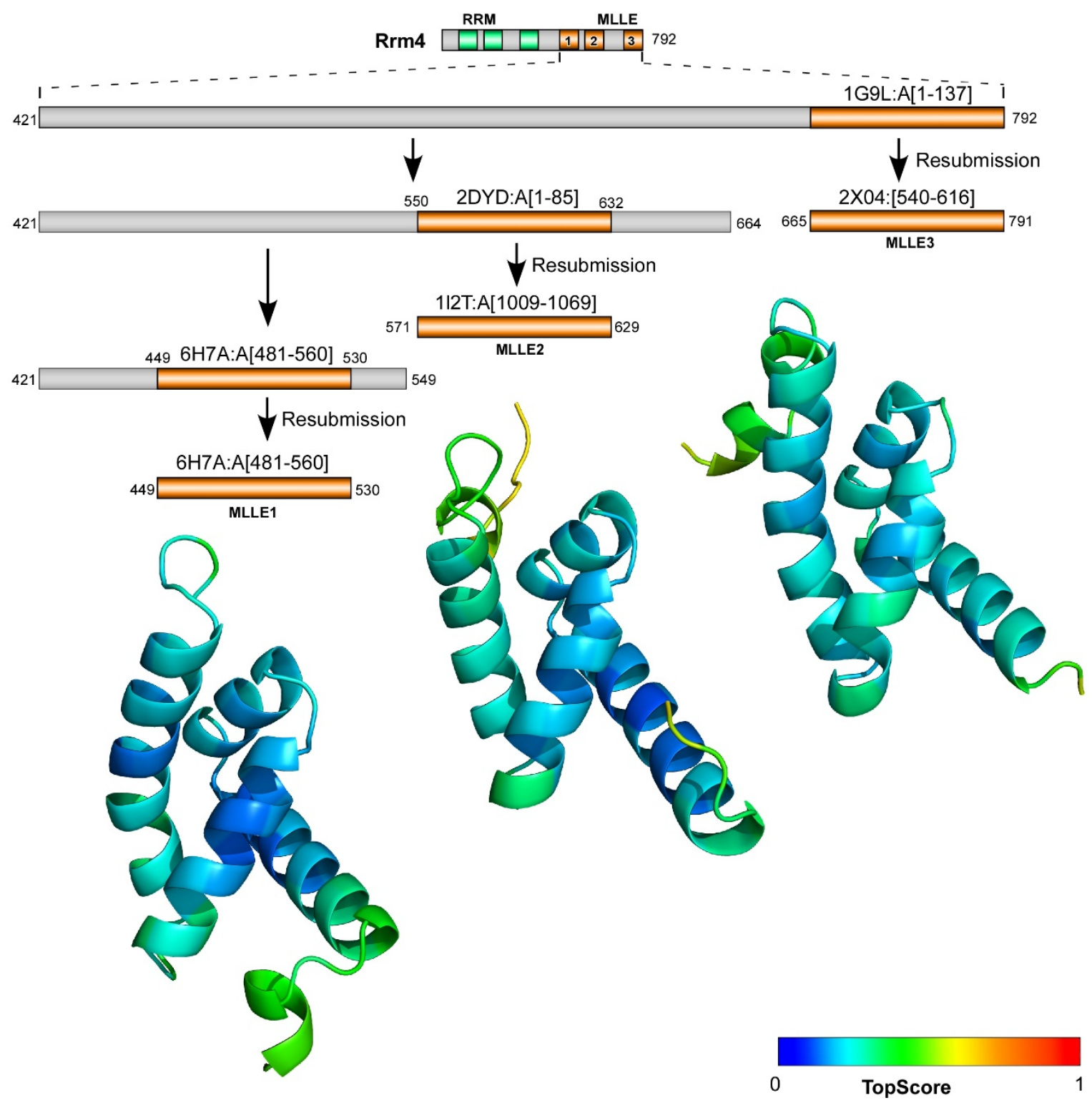

Figure 1. The C-terminal half of Rrm4 contains three MLLE domains.

828 (A) Schematic representation of protein variants drawn to scale (bar, 200 amino acids, number

829 of amino acids indicated next to protein bars) using the following colouring: dark green, RNA 830 recognition motif (RRM); orange, $\mathrm{MLLE}^{\mathrm{Rrm} 4}$ domains; dark blue, MLLE ${ }^{\text {Pab1}}$; light blue PAM2; 
Devan, Schott-Verdugo et al.

831 light orange PAM2L sequence (PL1 - 2) Ankyrin repeats (5xANK), FYVE domain, and RING

832 domain of Upal are given in dark grey. (B) Sequence alignment of previously determined

833 MLLE domains showing the degree of similarity to the three Rrm4-MLLE domains and the

834 positions (Hs - Homo sapiens, Ta - Triticum aestivum, La - Leishmania major, Sc -

835 Saccharomyces cerevisiae, Tc - Trypanosoma cruzi, Rn - Rattus norvegicus, Um - Ustilago

836 maydis, PABPC1, Pab1 - poly [A]-binding protein, UBR5 - E3 ubiquitin-protein ligase).

837 Accession number and sequence coverage are listed in the Appendix Table S1. Multiple

838 sequence alignment was performed by ClustalW. (C) Identification and modeling of C-terminal

839 MLLE domains of Rrm4. The iterative process is depicted graphically. The best identified

840 template for each run, and the region of that template that aligns with Rrm4, are displayed (see

841 also Fig. EV1A for the templates used for the final models). The structural models obtained are

842 shown for the span of the first identified template and are coloured according to their per-

843 residue TopScore, where the scale from 0 to 1 indicates a low to high local structural error. 
bioRxiv preprint doi: https://doi org/10.1101/2021.1025.465676. this version posted October 25, 2021. The copyright holder for this preprint (which was not certified by peer review) is the author/funder, who has granted bioRxiv a license to display the preprint in perpetuity. It is made available under aCC-BY-NC 4.0 International license.

Devan, Schott-Verdugo et al.

A

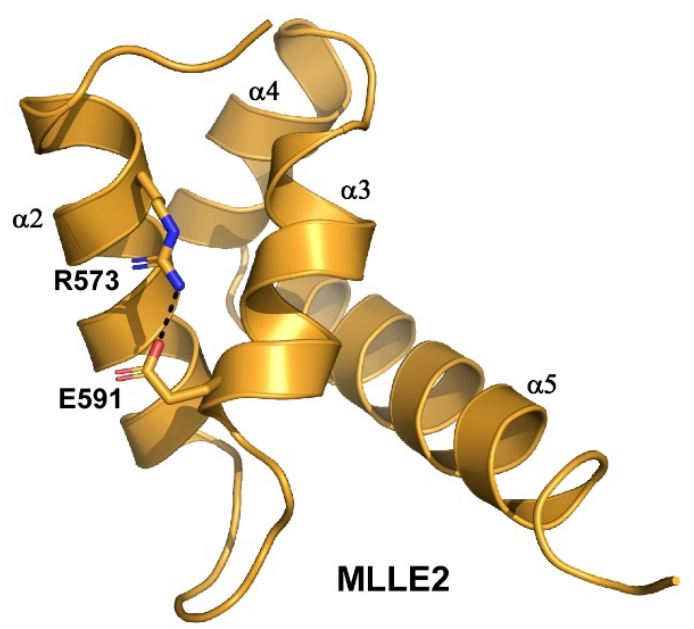

B

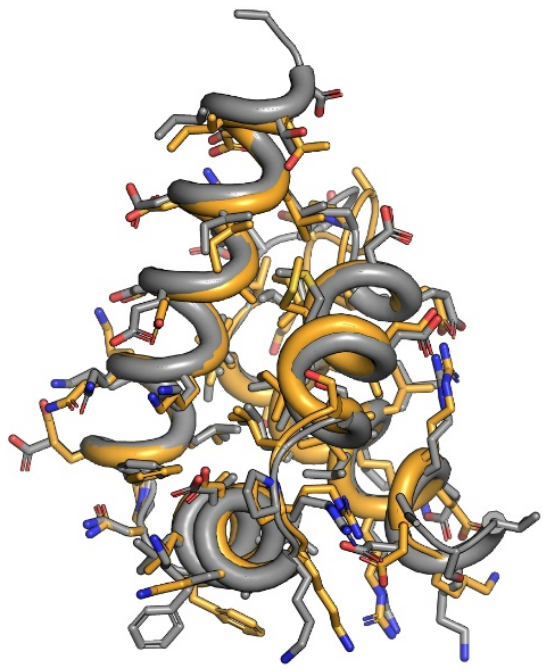

C

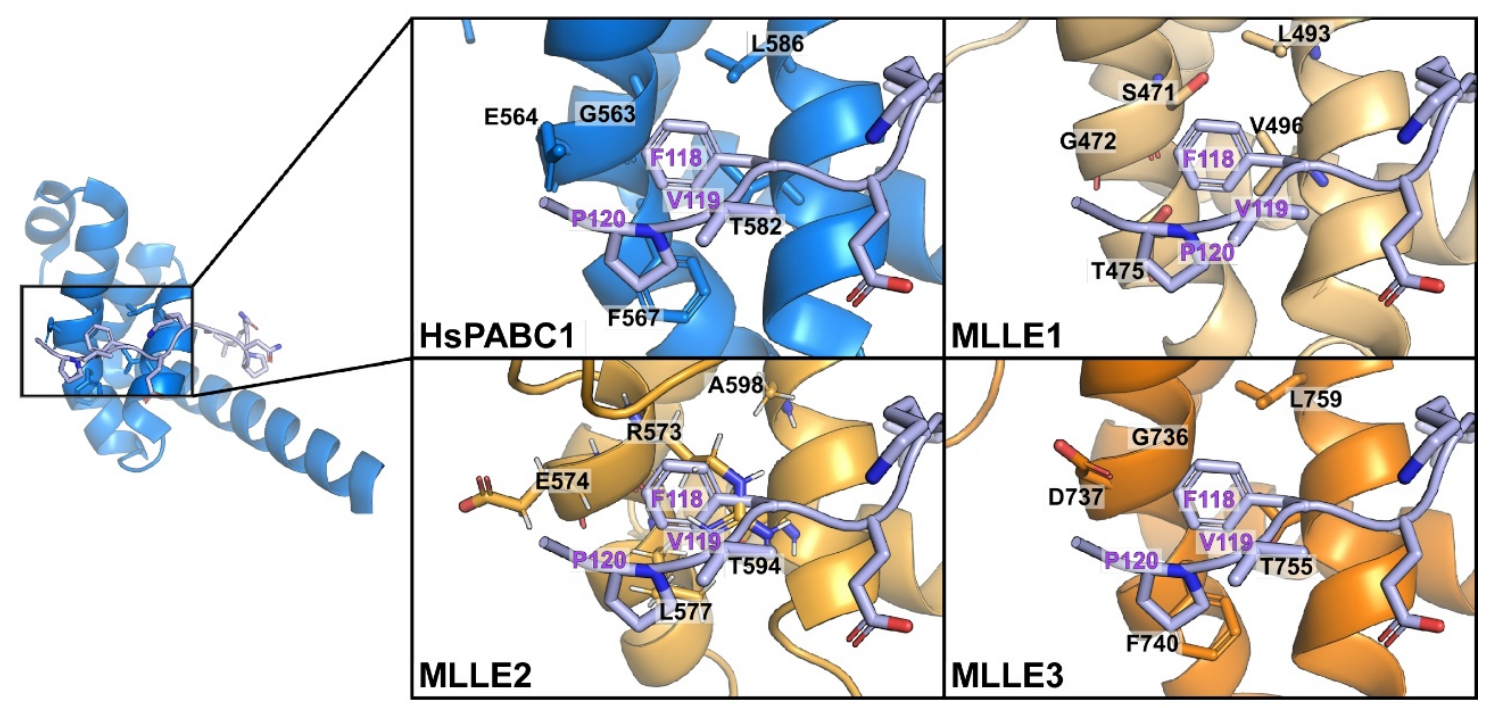

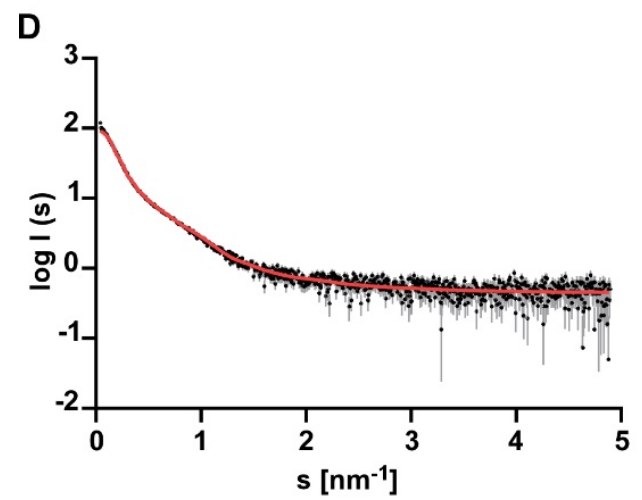

E

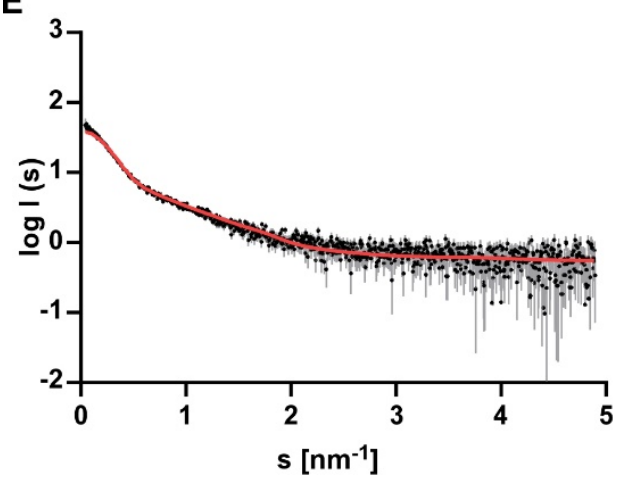

G-Rrm4

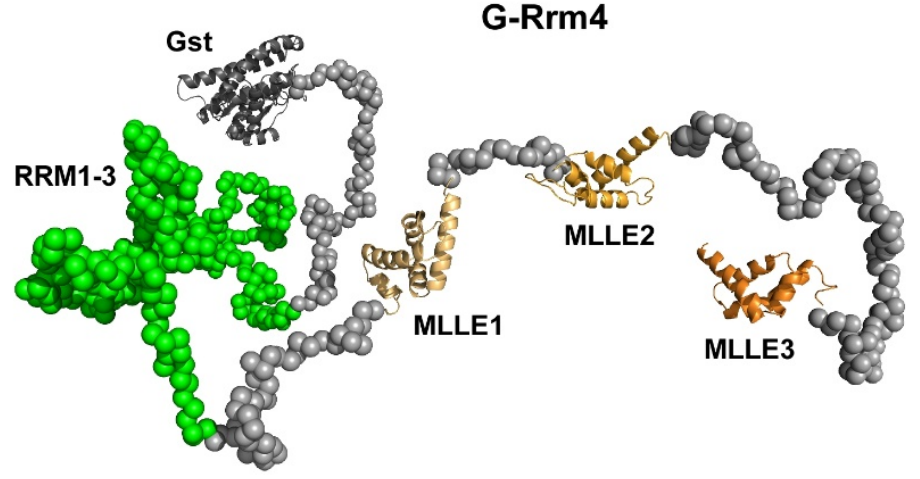

H-Rrm4-NT4

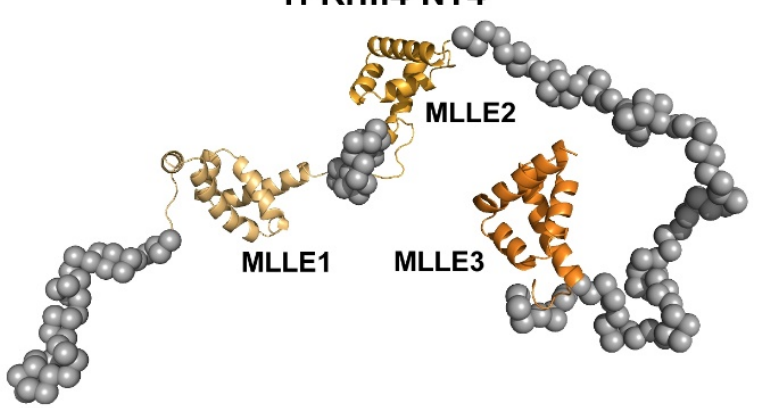


Devan, Schott-Verdugo et al.

Figure 2. Rrm4 contains a C-terminal tripartite MLLE binding platform

847 (A) Crystal structure of the MLLE2 domain is highlighted in orange. The four helices are 848 indicated by $\alpha 2-5$ according to the 5 helix nomenclature found in MLLE domains (Xie et al., 849 2014). Note that the first short helix $\alpha 1$ is missing. Arg573 and Glu591 are highlighted in 850 sticks. These sides chains would interfere with binding of the canonical Phe of PAM2 type 851 motifs. (B) Structural alignment of the MLLE2 model generated by TopModel and the X-ray 852 crystal structure of this domain (grey or orange, respectively). The all-atom RMSD is $0.69 \AA$, 853 resulting mostly from different rotamers of solvent-exposed sidechains. (C) Comparison of 854 peptide binding sites after structural alignment of the models of Rrm4 MLLE domains (orange 855 shades) and the canonical MLLE domain of HsPABPC1 (blue; PDB ID 3KUS) and manually 856 placing the PAM2 motif of PAIP2 (lilac). In the interaction of MLLE ${ }^{\text {PABPC1 }}$ with PAM2 of 857 PAIP2, Phe118 of PAM2 is the major determinant for binding and present in all the PAM2 858 motifs except LARP4a and b (Kozlov \& Gehring, 2010; Xie et al., 2014; Fig. EV3A). Of the 859 identified Rrm4 MLLE domains, only MLLE3 retains all sidechains that favour the binding of 860 this characteristic Phe; particularly, Gly736 should allow the Phe to bind into a pocket. MLLE1 861 and MLLE2 have Ser471 and Arg573 instead of G in this position, suggesting that Phe binding 862 would be sterically hindered in these interfaces. (D) left panel Experimental data curve for GST863 Rrm4 is shown in black dots with grey error bars, the EOM fit as a red line $\left(\chi^{2}=1.289\right)$. The 864 intensity is displayed as a function of momentum transfers. right panel. Selected model of the 865 EOM analysis from GST-Rrm 4 with a $R_{g}$ of $8.75 \mathrm{~nm}$, a $D_{\max }$ of $23.99 \mathrm{~nm}$ with a volume fraction 866 of 0.25. (E) left panel Experimental data curve for H-Rrm4NT4 is shown in black dots with 867 grey error bars, the EOM fit as red line $\left(\chi^{2}=1.262\right)$. The intensity is displayed as a function of 868 momentum transfers. right panel Selected model of the EOM analysis from H-Rrm4NT4 with 869 a $R_{g}$ of $5.10 \mathrm{~nm}$, a $D_{\max }$ of $16.43 \mathrm{~nm}$, and a volume fraction of $\sim 0.75$. The MLLE subdomains 870 are shown in cartoon representation (MLLE1 in light orange, MLLE2 in orange, MLLE 3 in 871 dark orange, and the GST in dark grey) and the missing amino acids as grey spheres (all other 872 models and the SAXS data are available in Figure EV2E).

873

874 
bioRxiv preprint doi: https://doi.org/10.1101/2021.10 25.465676; this version posted October 25, 2021. The copyright holder for this preprint (which was not certified by peer review) is the author/funder, who has granted bioRxiv a license to display the preprint in perpetuity. It is made available under aCC-BY-NC 4.0 International license.

Devan, Schott-Verdugo et al.

A

\begin{tabular}{|c|c|}
\hline & RRM MLLE \\
\hline Rrm4 & 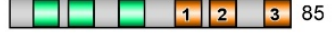 \\
\hline H-Rrm4-NT4 & 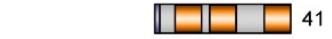 \\
\hline G-Rrm4-NT4 & \begin{tabular}{l|l|l} 
GST & $\square$
\end{tabular} \\
\hline G-Rrm4-NT4-M1 $1 \Delta$ & \begin{tabular}{|l|l|l|l|l|l|} 
GST & $\square 8$
\end{tabular} \\
\hline G-Rrm4-NT4-M2 $\Delta$ & \begin{tabular}{|l|l|l|l|} 
GST & \\
\end{tabular} \\
\hline G-Rrm4-NT4-M3 $\Delta$ & \begin{tabular}{|l|l|l|l|l|} 
est & -1 \\
\end{tabular} \\
\hline G-Rrm4-NT4-M1,2 & \begin{tabular}{|l|l|} 
est \\
\end{tabular} \\
\hline Pab1 & 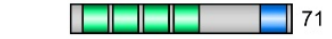 \\
\hline LE & 37 \\
\hline
\end{tabular}

Upa1

Sumo-PAM2 $2^{\text {Upa1 }}$

SUMO-PAM2L1Upa1

Sumo-PAM2L2 $2^{\mathrm{UPa} 1}$

PAM2 $2^{\text {Upa1 }}$

PAM2L1Upa1

PAM2L2 ${ }^{\text {Upa1 }}$
PAM2 PAM2L1 5XANK PAM2L2 FYVE RING || ||

\begin{tabular}{ll}
\hline \\
SOSTLSPNASVFKPSRS
\end{tabular}

B G-Rrm4-NT4
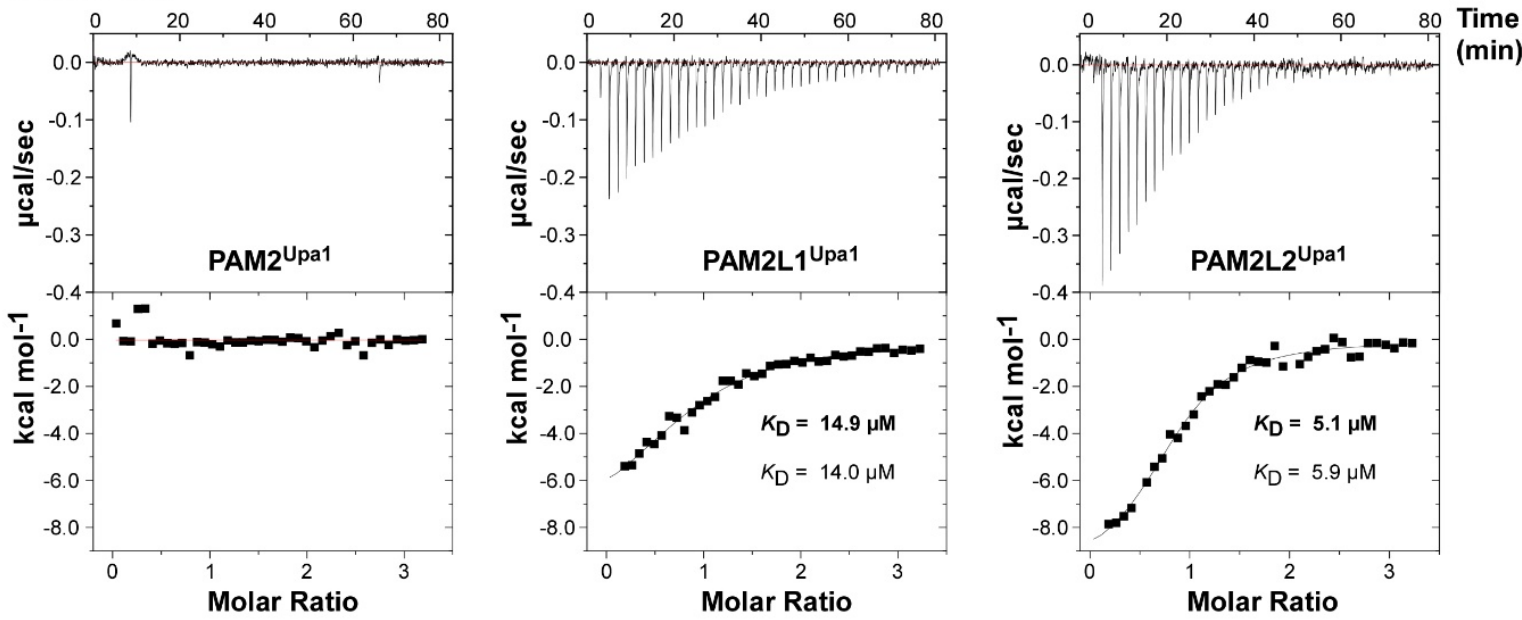

C G-Rrm4-NT4-M3 $\Delta$
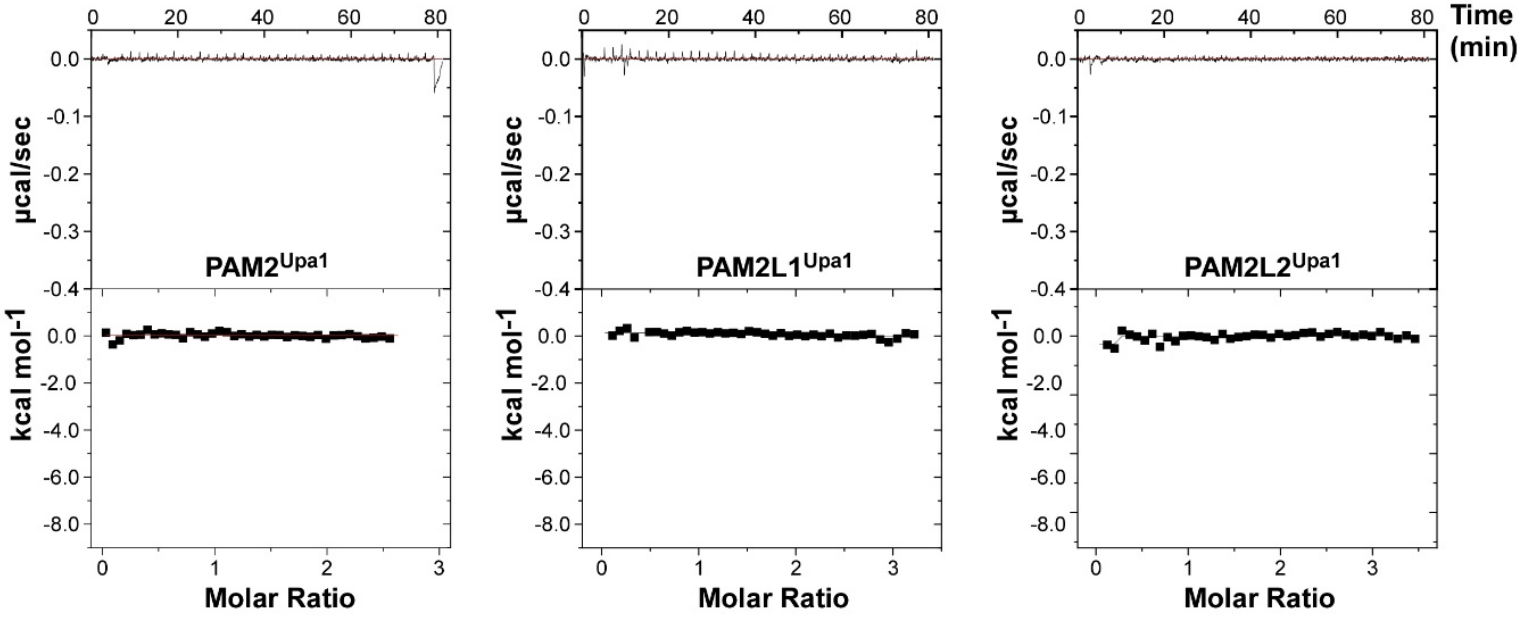

D G-Rrm4-NT4-M1,2 $\Delta$
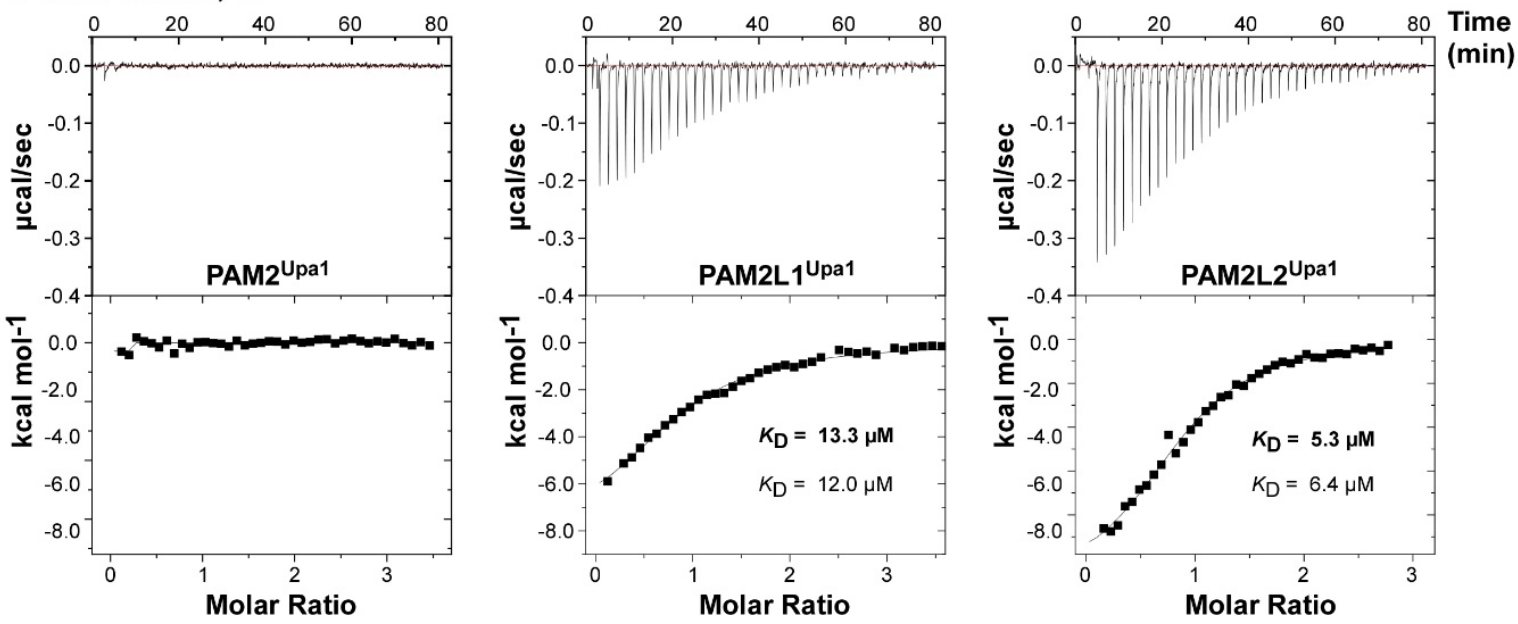
Devan, Schott-Verdugo et al.

\section{Figure 3. MLLE3 ${ }^{\text {Rrm4 }}$ is crucial for PAM2L1 ${ }^{\text {Upa1 }}$ and PAM2L2 ${ }^{\text {Upa1 }}$ binding.}

877 (A) Schematic representation of protein variants (Molecular weight in kilo Dalton indicated) 878 using the following colouring: dark green, RNA recognition motif (RRM); orange, MLLE ${ }^{\text {Rrm4 }}$

879 domains; dark blue, MLLE ${ }^{\text {Pab1; }}$ light blue PAM2; light orange PAM2L sequence (PL1 - 2).

880 Ankyrin repeats (5xANK), FYVE domain, and RING domain of Upa1 are given in dark grey.

881 GST and SUMO tags are labelled. Amino acids of the FxP and FxxP of PAM2 and PAM2L

882 sequences are printed in grey fond. (B-D) Representative isothermal titration calorimetry (ITC)

883 binding curves of MLLE domains. Experiments were performed using GST- or Histidine-

884 tagged MLLE variants and synthetic PAM2 peptide variants. $K_{\mathrm{D}}$ values of two independent 885 measurements are given (values corresponding to the indicated data are given in bold). 
bioRxiv preprint doi: https://doi.org/10.1101/2021.10.25.465676; this version posted October 25, 2021. The copyright holder for this preprint (which was not certified by peer review) is the author/funder, who has granted bioRxiv a license to display the preprint in perpetuity. It is made available under aCC-BY-NC 4.0 International license.

Devan, Schott-Verdugo et al.

A
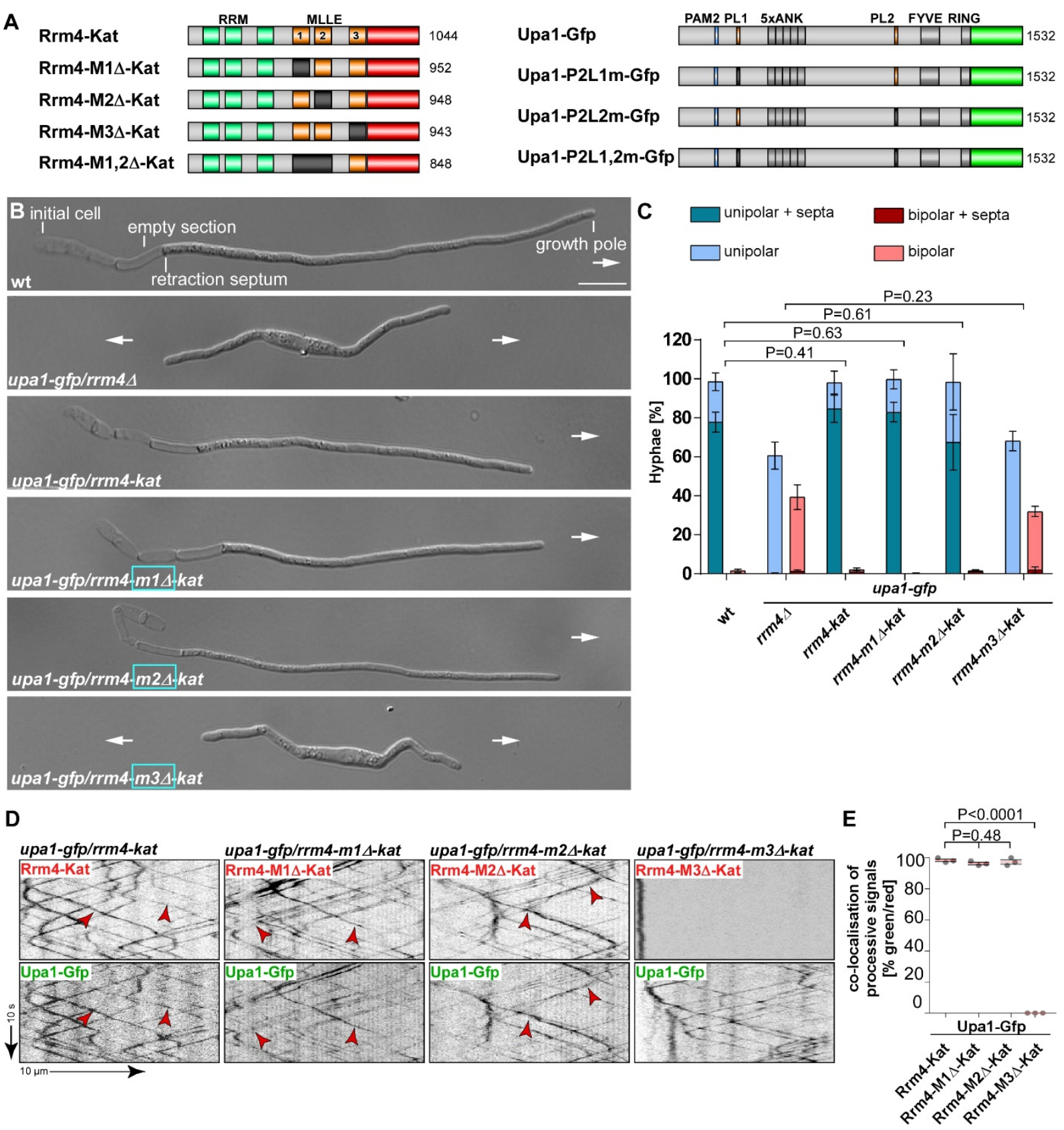

Figure 4. MLLE3 is key for endosomal mRNA transport.

889 (A) Schematic representation of Rrm4 and Upa1 variants drawn not to scale (number of amino 890 acids indicated next to protein bars) using the following colouring: dark green, RNA recognition 891 motif (RRM); orange, MLLE domains; red, mKate2, blue, PAM2, light orange PAM2 like 892 sequence (PL1 - 2) and light green, Gfp. Ankyrin repeats (5xANK), FYVE domain and RING 893 domain of Upa1 are given in dark grey. (B) Growth of AB33 derivatives in their hyphal form 894 (6 h.p.i.; size bar $10 \mu \mathrm{m}$ ). Growth direction is marked by arrows. (C) Quantification of hyphal 895 growth of AB33 derivatives shown in B (6 h.p.i.): unipolarity, bipolarity and basal septum 896 formation were quantified (error bars, SEM.; $\mathrm{n}=3$ independent experiments, $>100$ hyphae 897 were counted per strain; for statistical evaluation, the percentage of uni- and bipolarity was 898 investigated by using unpaired two-tailed Student's t-test $(\alpha<0.05)$. (D) Kymographs of AB33 899 hyphae derivatives (6 h.p.i.; inverted fluorescence images) expressing pairs of red and green 900 fluorescent proteins as indicated. Fluorescence signals were detected simultaneously using 
Devan, Schott-Verdugo et al.

901 dual-view technology (arrow length on the left and bottom indicates time and distance,

902 respectively). Processive co-localising signals are marked by red arrowheads. (E) Percentage 903 of processive signals exhibiting co-localisation for strains shown in D (data points represent 904 means from $\mathrm{n}=3$ independent experiments, with mean of means, red line and SEM; unpaired 905 two-tailed Student's t-test $(\alpha<0.05)$; for each experiment, 10 hyphae per strains were analysed). 
Devan, Schott-Verdugo et al.
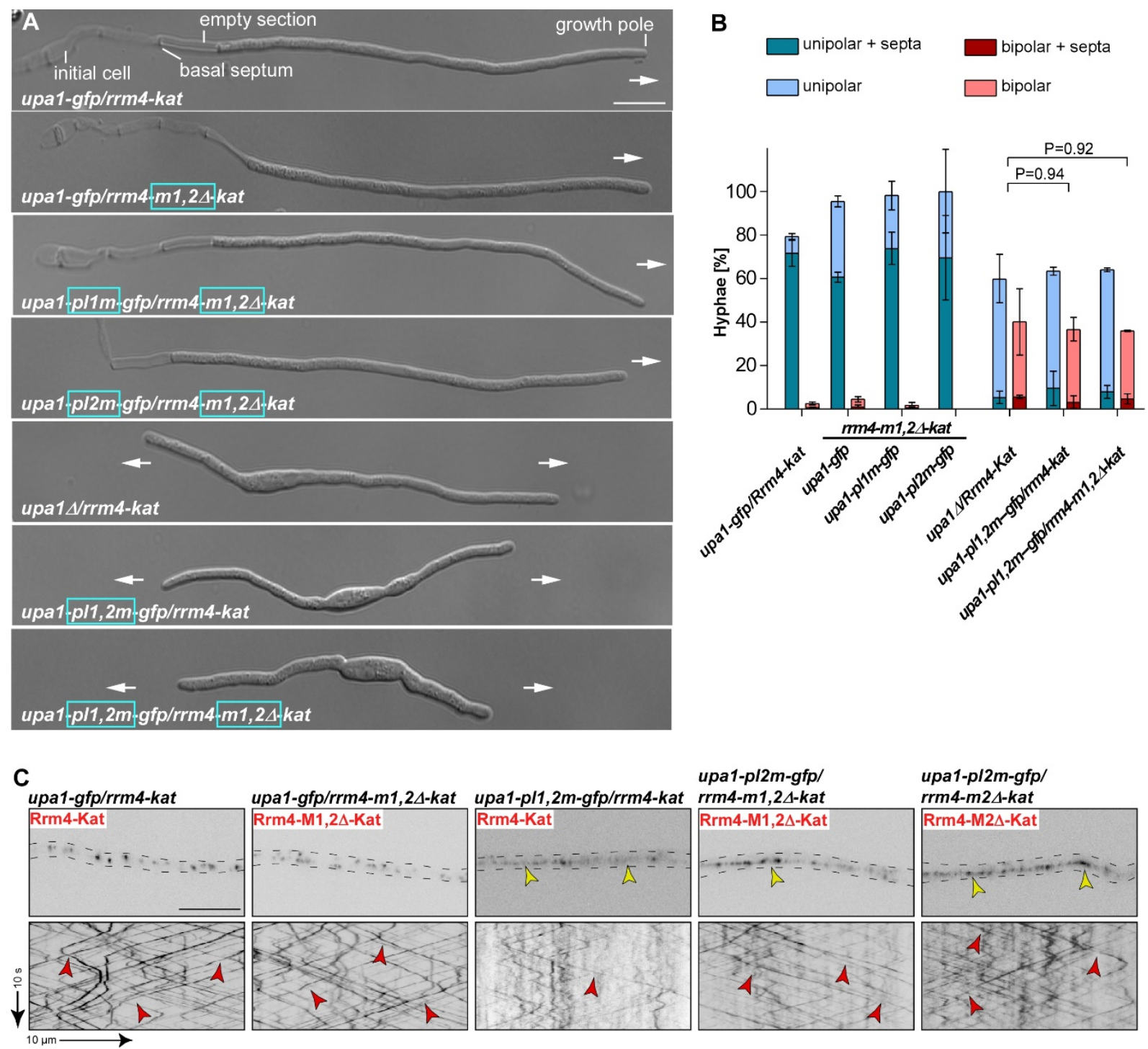

D
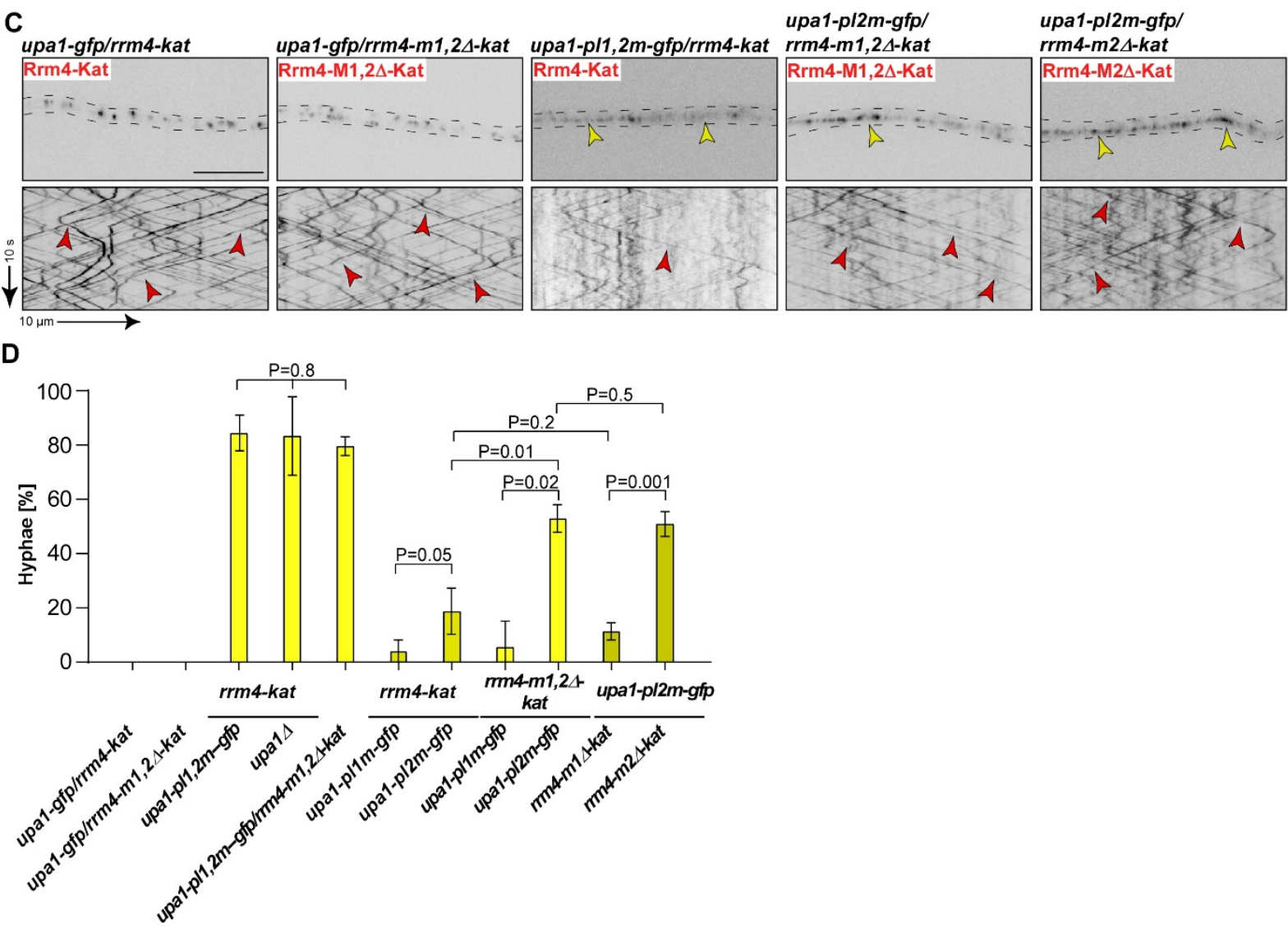

Figure 5. MLLE2 plays an accessory role in endosomal attachment of Rrm4

910 (A) Growth of AB33 derivatives in their hyphal form (6 h.p.i.; size bar $10 \mu \mathrm{m})$. Growth

911 direction is marked by arrows. (B). Quantification of hyphal growth of AB33 derivatives shown 912 in A (6 h.p.i.): unipolarity, bipolarity and basal septum formation were quantified (error bars, 
Devan, Schott-Verdugo et al.

913 SEM; $\mathrm{n}=3$ independent experiments, $>100$ hyphae were analysed per strain; For statistical

914 analysis, the percentage of uni- and bipolarity was investigated by using unpaired two-tailed

915 Student's t-test $(\alpha<0.05)$. (C) Micrographs (inverted fluorescence image; size bar, $10 \mu \mathrm{m})$ and

916 corresponding kymographs of AB33 hyphae derivatives (6 h.p.i.) co-expressing various Upa1-

917 Gfp and Rrm4-Kat versions as indicated. Movement of Rrm4-Kat versions is shown (arrow

918 length on the left and bottom indicates time and distance, respectively). Bidirectional movement

919 is visible as diagonal lines (red arrowheads). Aberrant microtubule staining is indicated by a

920 yellow arrowhead. (D) Percentage of hyphae (6 h.p.i.) exhibiting aberrant microtubule

921 association as indicated in panel C and EV5C. Set of strains that were analysed simultaneously

922 are shown in the same yellow shading (error bars, SEM; for statistical evaluation, the percentage

923 of hyphae with abnormal microtubule staining was compared by using unpaired two-tailed

924 Student's t-test $(\alpha<0.05) ; \mathrm{n}=3$ independent experiments, $>25$ hyphae were analysed per

925 strain).

926

927 
Devan, Schott-Verdugo et al.

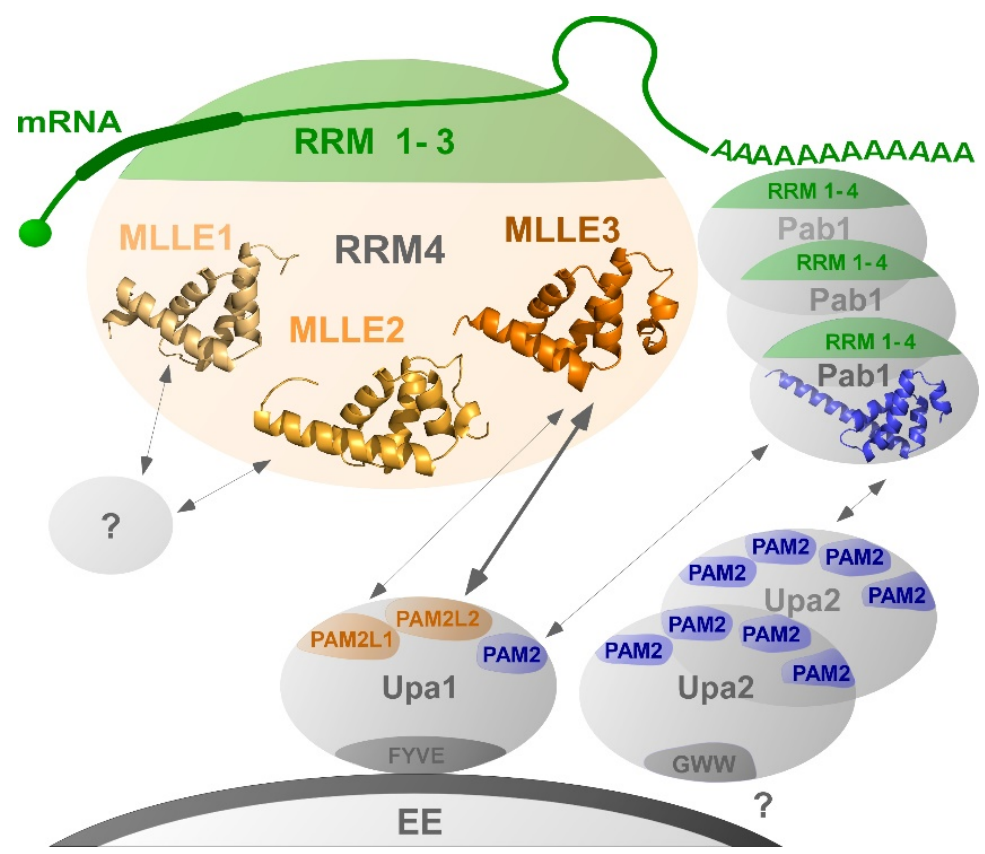

930 Cargo mRNAs (green) are bound by the N-terminal RRM domains of Rrm4 (green). The C 931 terminal MLLE domains (orange) form a binding platform: MLLE3 ${ }^{\text {Rrm4 }}$ interacts with 932 PAM2L1 ${ }^{\text {Upa1 }}$ and PAM2L2 ${ }^{\text {Upa1 }}$ (orange), MLLE1 and $-2^{\text {Rrm4 }}$ might interact with a currently 933 unknown factor to support endosomal binding. The four RRMs of Pab1 (green) interact with 934 the poly(A) tail, and the MLLE ${ }^{\text {Pab1 }}$ (blue) interacts with PAM2 of Upa1 and with the four PAM2 935 motifs of Upa2 (dark blue), a dimerising scaffold protein. Upa1 is attached to endosomes via 936 its FYVE domain, and the C-terminal GWW motif of Upa2 is crucial for its endosomal binding. 
bioRxiv preprint doi: $\mathrm{https}$ //doi.org/10.1101/2021.10.25.465676. this version posted October 25, 2021. The copyright holder for this preprint (which was not certified by peer review) is the author/funder, who has granted bioRxiv a license to display the preprint in perpetuity. It is made available under aCC-BY-NC 4.0 International license.

Devan, Schott-Verdugo et al.

Expanded View Figures

A

\begin{tabular}{|l|c|c|c|c|}
\hline \multirow{2}{*}{ Domain } & Templates $^{\mathbf{a}}$ & Rrm4 span & Template span & $\begin{array}{c}\text { Identity } \\
\text { (Similarity) }^{\mathbf{b}}\end{array}$ \\
\hline \multirow{3}{*}{ MLLE1 } & 6H7A:A & $451-529$ & $481-560$ & $22.1(38.4)$ \\
\cline { 2 - 5 } & 3PTH:A & $451-528$ & $544-618$ & $18.4(34.5)$ \\
\cline { 2 - 5 } & 112T:A & $464-528$ & $1009-1069$ & $25.8(40.9)$ \\
\hline \multirow{3}{*}{ MLLE2 } & 112T:A & $571-629$ & $1009-1069$ & $23.8(44.4)$ \\
\cline { 2 - 5 } & 3KTP:A & $550-631$ & $554-620$ & $17.6(35.3)$ \\
\cline { 2 - 5 } & 3KUR:A & $550-627$ & $554-616$ & $18.5(37.0)$ \\
\hline \multirow{3}{*}{ MLLE3 } & 2X04:A & $712-791$ & $540-616$ & $30.6(44.7)$ \\
\cline { 2 - 5 } & 3KUR:A & $716-791$ & $544-616$ & $32.9(45.6)$ \\
\cline { 2 - 5 } & 3KTP:A & $716-791$ & $544-616$ & $32.9(45.6)$ \\
\hline
\end{tabular}

a. PDB ID and chain identifier. b. in percentage

B
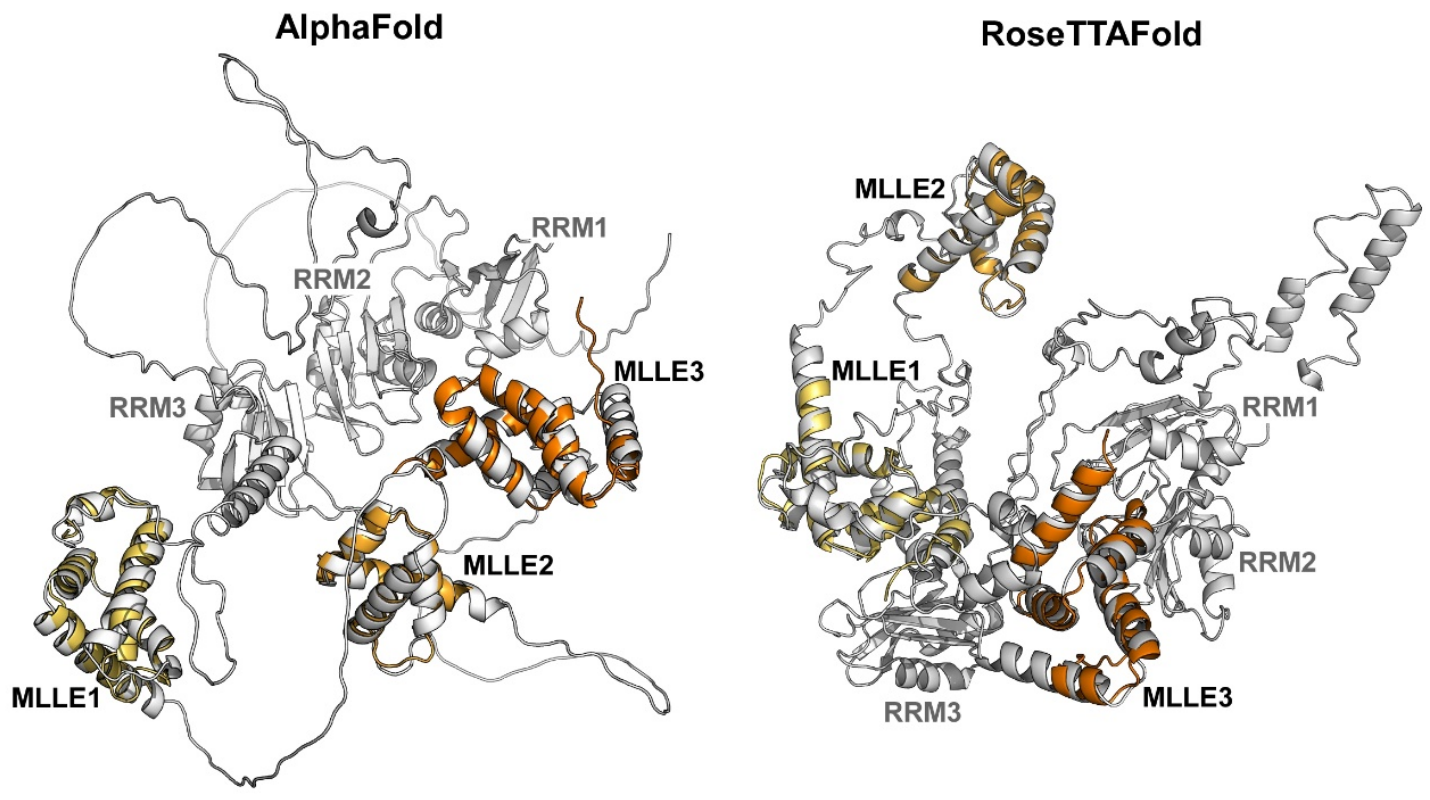

Figure EV1. The presence of three MLLEs is verified by additional modeling predictions.

941 (A) Compilation of MLLE sequences used for modeling with the highest similarity of MLLE1-

$942 \quad 3^{\mathrm{Rrm} 4}$. (B) Structural models obtained with TopModel overlaid to Rrm4 full-length models 943 obtained with the recently available tools as indicated. Natural alignments between 944 corresponding MLLE domains have an RMSD $<2 \AA$, mutually confirming the quality of the 945 independently modeled structures. The differences in the relative domain arrangements in both 946 full-length models and the disordered regions in between the domains suggest a high mobility 947 within Rrm4. 


\section{Devan, Schott-Verdugo et al.}

A

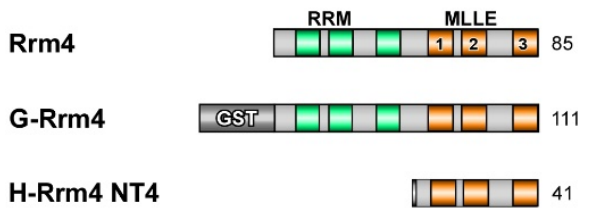

D

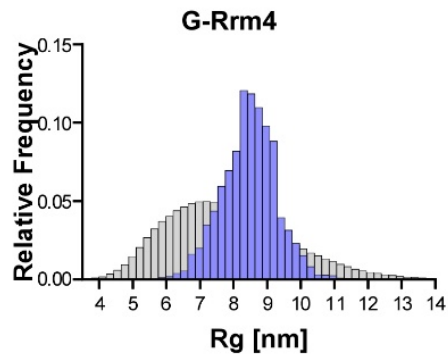

B

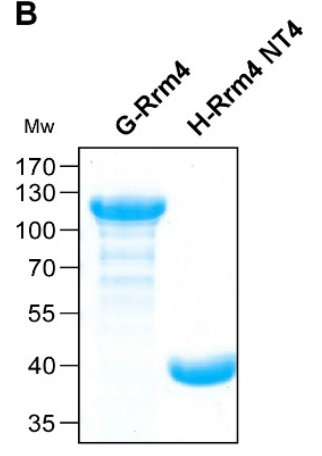

C

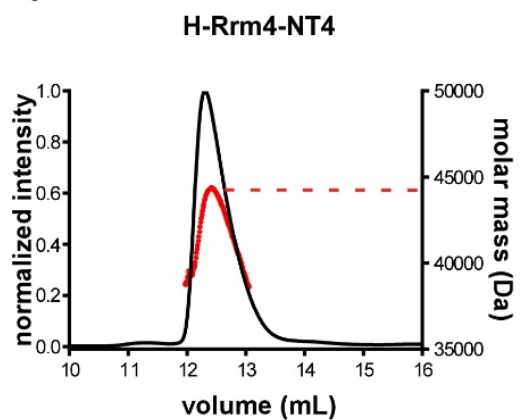

H-Rrm4-NT4

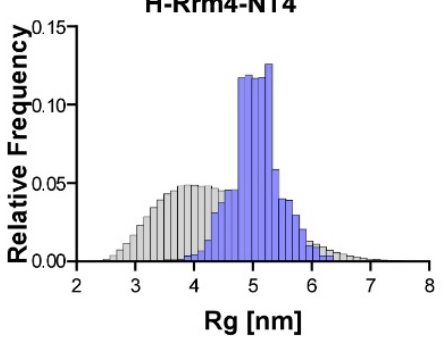

E

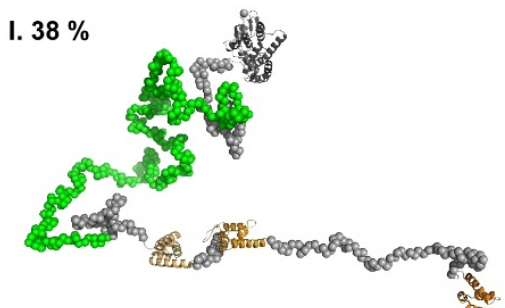

II. $25 \%$

III. $12 \%$

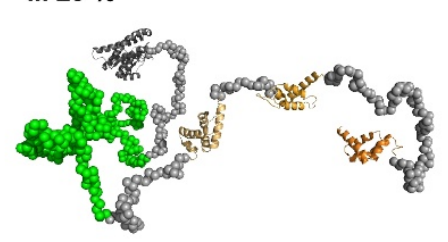

LItr"

IV $12 \%$

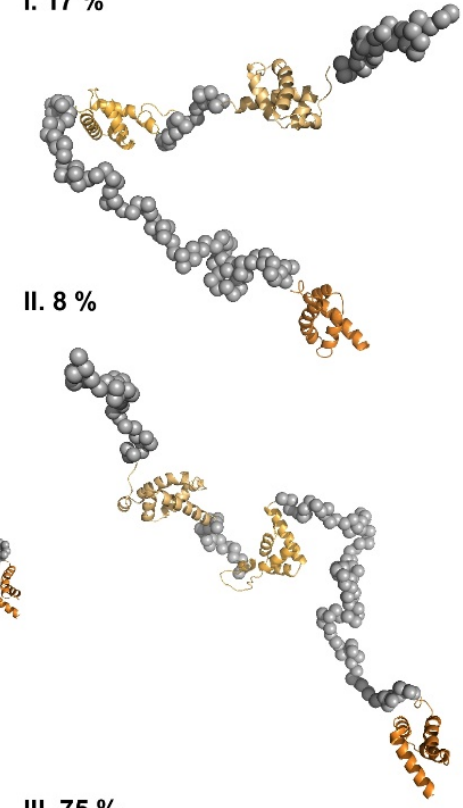

III. $75 \%$
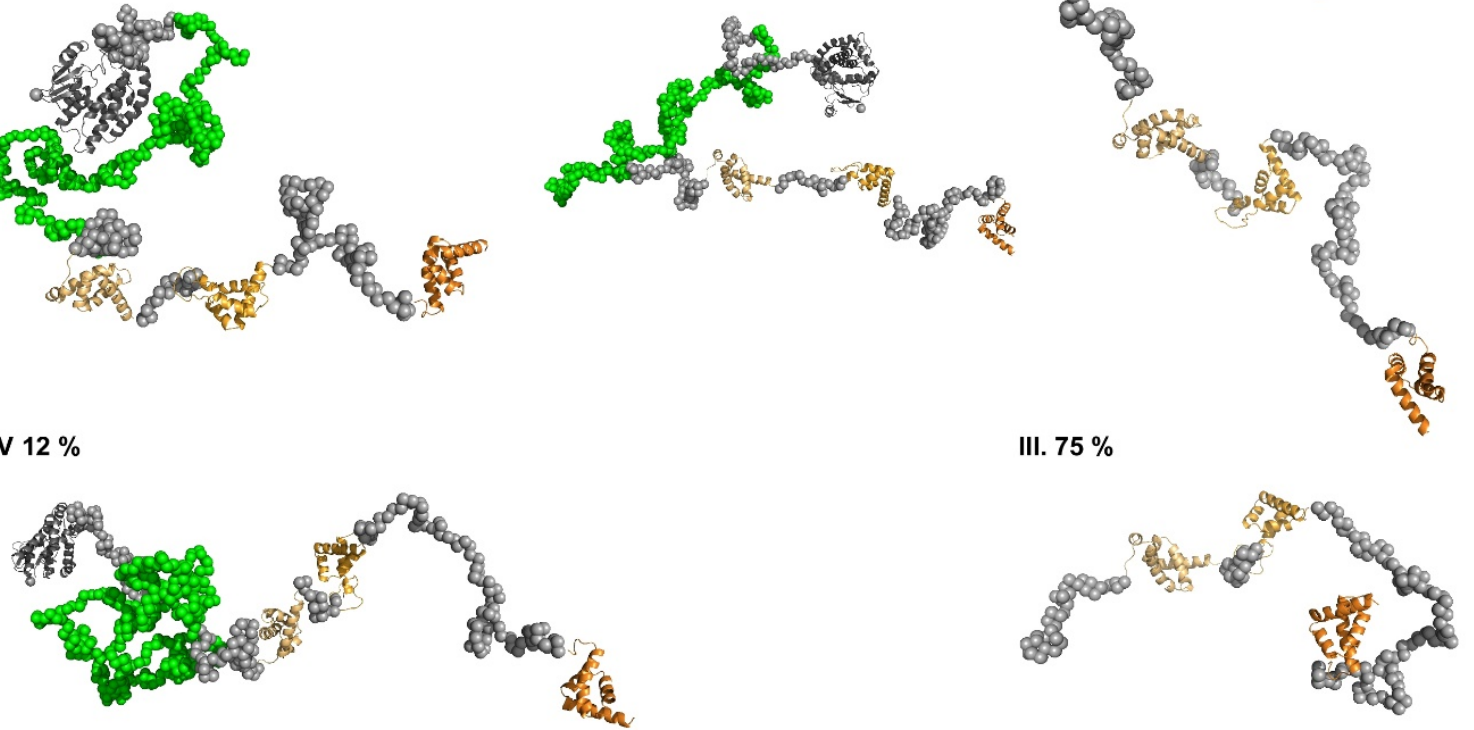

Figure EV2. The three MLLEs of Rrm4 are located in a flexible C-terminal region.

952 (A) Schematic representation of protein variants drawn to scale (molecular weight in kilo 953 Dalton indicated next to protein bar ) using the following coloring: dark green, RNA recognition 954 motif (RRM); orange, MLLE ${ }^{\mathrm{Rrm} 4}$ domains; (B) SDS PAGE analysis of purified G-Rrm4, H955 Rrm4-NT4 used in crystallography and SAXS measurement. (C) MALS-SEC analysis of H956 Rrm4-NT4. Graph shows the elution profile. Dotted line in red indicate the apparent molecular 
Devan, Schott-Verdugo et al.

957 weight as observed in the light scattering. (D) $R_{g}$ distribution calculated by EOM pool is shown 958 in grey bars and the selected models in blue bars left GST_Rrm4 right H-Rrm4NT4 (E) Left 959 Selected models of the EOM analysis for GST-Rrm4. The MLLE subdomains and the GST are 960 shown in cartoon representation (MLLE1 in light orange, MLLE2 in orange, MLLE 3 in dark 961 orange) and the missing amino acids as grey spheres. I: The model has a $R_{g}$ of $8.94 \mathrm{~nm}$, a $D_{\max }$ 962 of $29.22 \mathrm{~nm}$ with a volume fraction of $\sim 0.38$. II: The model has a $R_{g}$ of $8.75 \mathrm{~nm}$, a $D_{\max }$ of 23.99 963 with a volume fraction of $\sim 0.25$. III: The model has a $R_{g}$ of $7.74 \mathrm{~nm}$, a $D_{\max }$ of 25.90 with a 964 volume fraction of $\sim 0.12$. IV: The model has a $R_{g}$ of $8.33 \mathrm{~nm}$, a $D_{\max }$ of 28.79 with a volume 965 fraction of $\sim 0.12$. V: The model has a $R_{g}$ of $9.14 \mathrm{~nm}$, a $D_{\max }$ of 33.73 with a volume fraction 966 of 0.12. Right Selected models of the EOM analysis for H-Rrm4NT4. The MLLE subdomains 967 are shown in cartoon representation (MLLE1 in light orange, MLLE2 in orange, MLLE3 in 968 dark orange) and the missing amino acids as grey spheres. I: The model has a $R_{g}$ of $5.12 \mathrm{~nm}$, 969 a $D_{\max }$ of 15.56 with a volume fraction of 0.17 . II: The model has a $R_{g}$ of $5.90 \mathrm{~nm}$, a $D_{\max }$ of $97018.73 \mathrm{~nm}$ with a volume fraction of $\sim 0.08$. III: The model has a $R_{g}$ of $5.10 \mathrm{~nm}$, a $D_{\max }$ of 16.43 $971 \quad \mathrm{~nm}$ with a volume fraction of $\sim 0.75$. 
bioRxiv preprint doi: https//doi.org/10.1101/2021.10 25.465676 this version posted October 25,2021 . The copyright holder for this preprint (which was not certified by peer review) is the author/funder, who has granted bioRxiv a license to display the preprint in perpetuity. It is made available under aCC-BY-NC 4.0 International license.

Devan, Schott-Verdugo et al.

A

HsUSP10

HsGW182

HsMkrn1

HsPaip1

HsPaip2

HsAtx2

HsNFX1-123

HseRF 3a-N

HseRF $3 a-C$

HSPAN3

UmUpa1-PAM2

HSLARP 4

HSLARP 4b

HsTob

HSHECT-PAM2I

UmUpa1-PAM2L1

UmUpa1-PAM2L2

C

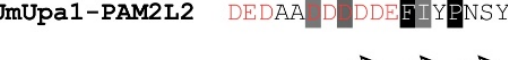

B

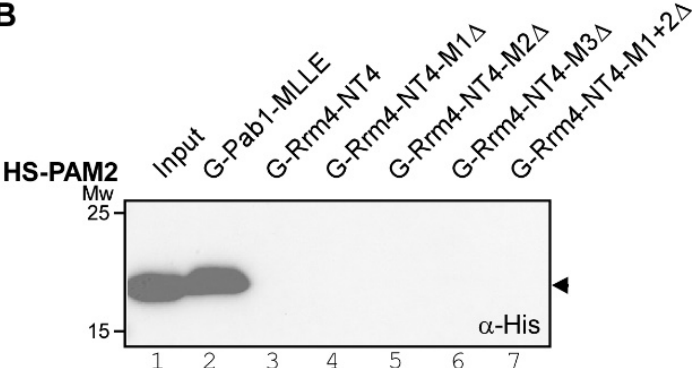

HS-PAM2L1

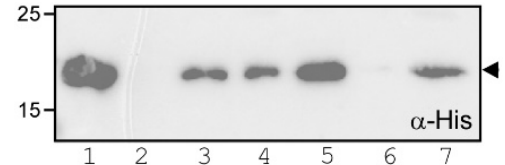

HS-PAM2L2
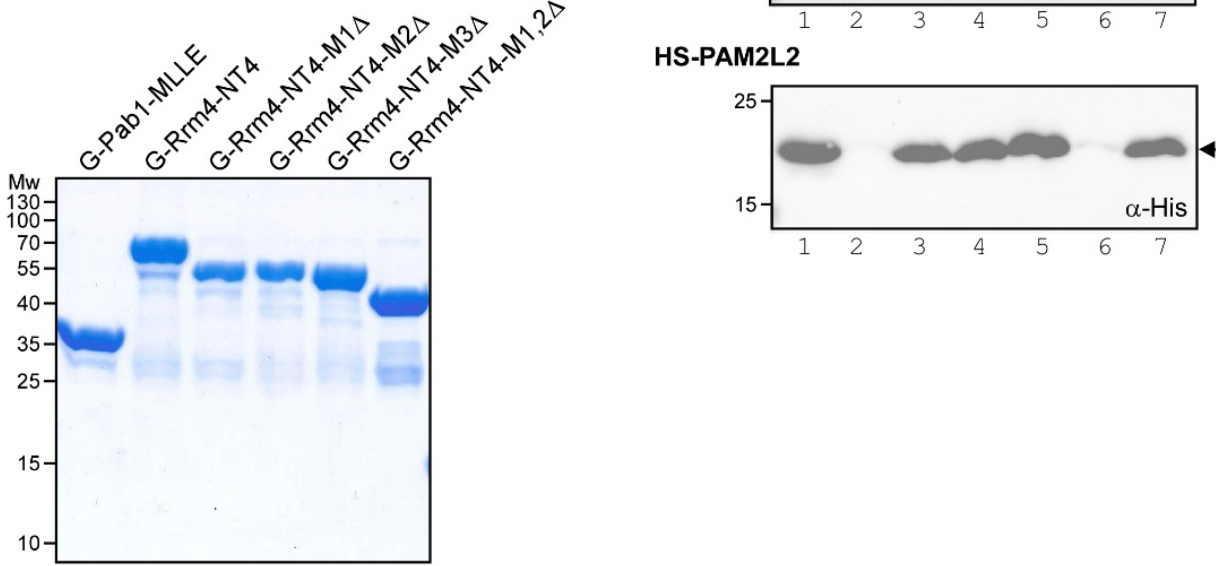

D G-Pab1-MLLE
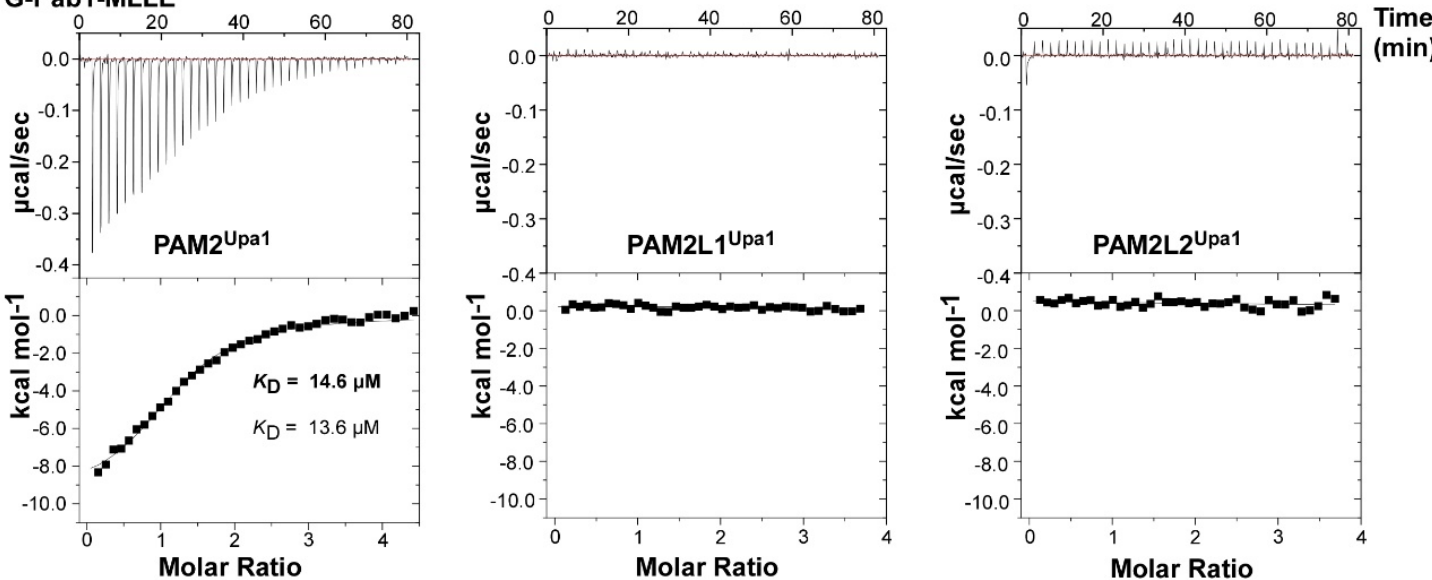

E

\section{G-Rrm4-NT4-M1 $\Delta$}
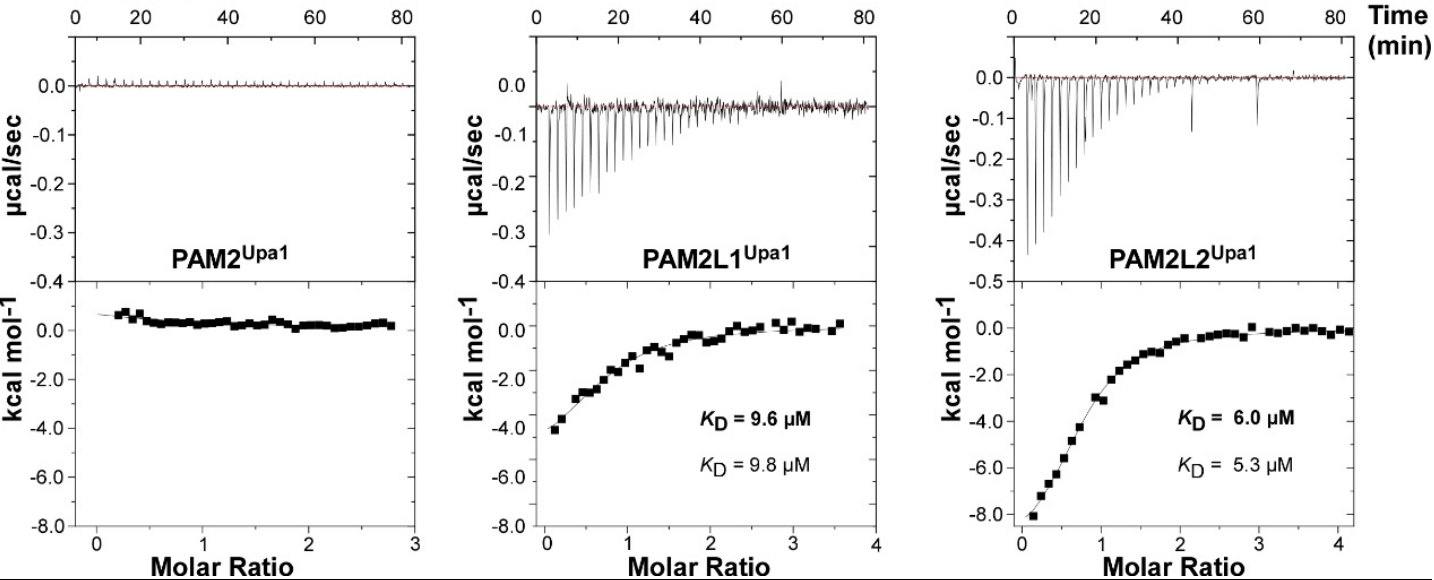

Continued on next page 
Devan, Schott-Verdugo et al.

F G-Rrm4-NT4-M2 $\Delta$
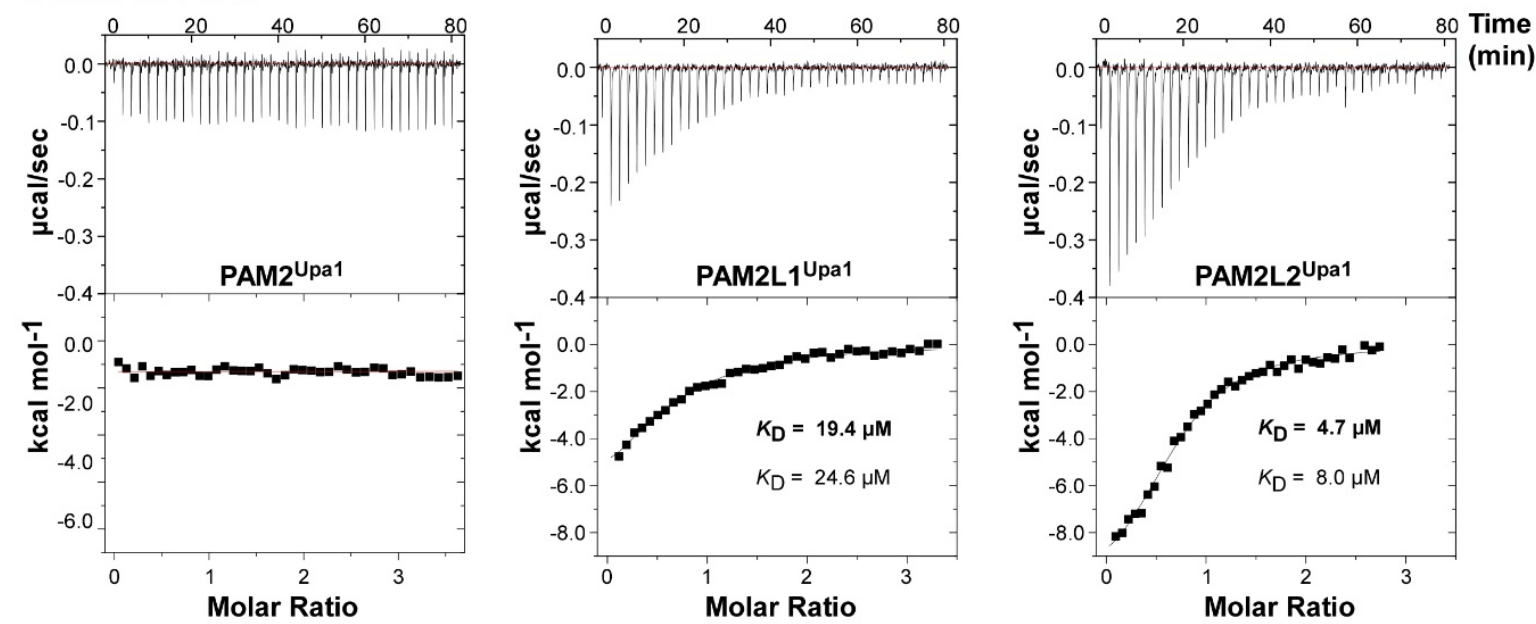

G H-Rrm4-NT4
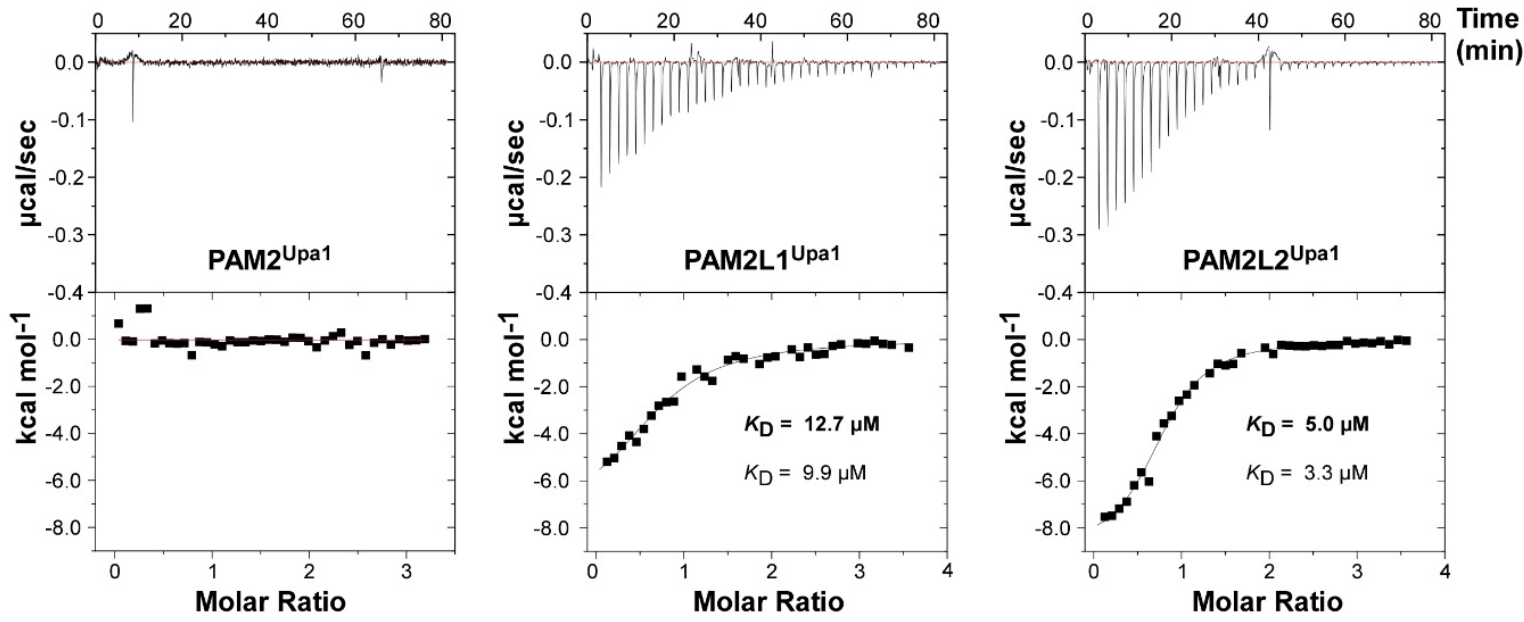

H

\begin{tabular}{|l|l|l|l|}
\hline \multirow{2}{*}{ G-Pab1-MLLE } & PAM2 Upa1 & PAM2L1 Upa1 & PAM2L2 Upa1 \\
\cline { 2 - 4 } G-Rrm4-NT4 & $14.6 / 13.6$ & No binding & No binding \\
\hline G-Rrm4-NT4-M1 $\Delta$ & No binding & $14.9 / 14.0$ & $5.1 / 5.9$ \\
\hline G-Rrm4-NT4-M2 $\Delta$ & No binding & $19.4 / 24.6$ & $6.7 / 8.0$ \\
\hline G-Rrm4-NT4-M3 $\Delta$ & No binding & No binding & No binding \\
\hline G-Rrm4-NT4-M1,2 $\Delta$ & No binding & $13.3 / 12.0$ & $5.3 / 6.4$ \\
\hline H-Rrm4-NT4 & No binding & $12.7 / 9.9$ & $5.0 / 3.3$ \\
\hline
\end{tabular}

Figure EV3. MLLE1 ${ }^{\text {Rrm4 }},-^{\text {Rrm4 }}$ are not essential for PAM2L1 ${ }^{\text {Upa1 }}$ and -L2 ${ }^{\text {Upa1 }}$ binding.

(A) Comparison of PAM2 sequences found in Upa1 (UniprotKB ID A0A0D1E015) with those of human proteins, such as Usp10 (Q14694), GW182 Q9HCJ0), Mkrn1 (Q9UHC7), Paip1 (Q9H074), Paip2 (Q9BPZ3), Atx2 (-Q99700), NFX (Q12986 ), eRF3 (P15170), PAN3

980 (Q58A45), LARP4 (Q71RC2), LARP4b (Q92615), Tob (P50616), HECT (O95071), Asp and Glu are indicated in red stressing the highly negative charges in PAM2L sequences. 
Devan, Schott-Verdugo et al.

982 Western blot analysis of GST co-purification experiments with components expressed in $E$. 983 coli: N-terminal Hexa-Histidine-SUMO-tagged PAM2 variants were pulled down by N984 terminal GST fused MLLE variants of Rrm4 and Pab1. Experiment was performed with the 985 soluble fraction of $E$. coli cell lysate to demonstrate specific binding. Results were analysed 986 with $\alpha$ His immunoblotting (C) SDS PAGE analysis of purified GST-MLLE variants used in 987 ITC experiments (D-G) Representative isothermal titration calorimetry (ITC) binding curves 988 of MLLE domains. Experiments were performed using GST or hexa-histidine-tagged MLLE 989 variants and synthetic PAM2 peptide variants. $K_{\mathrm{D}}$ values of two independent measurements are 990 given (values corresponding to the indicated data are given in bold). (H) Summary of ITC 991 results shown in the Fig3 and Fig EV3. $K_{\mathrm{D}}$ values are given in $\mu \mathrm{M}$. 


\section{Devan, Schott-Verdugo et al.}

A
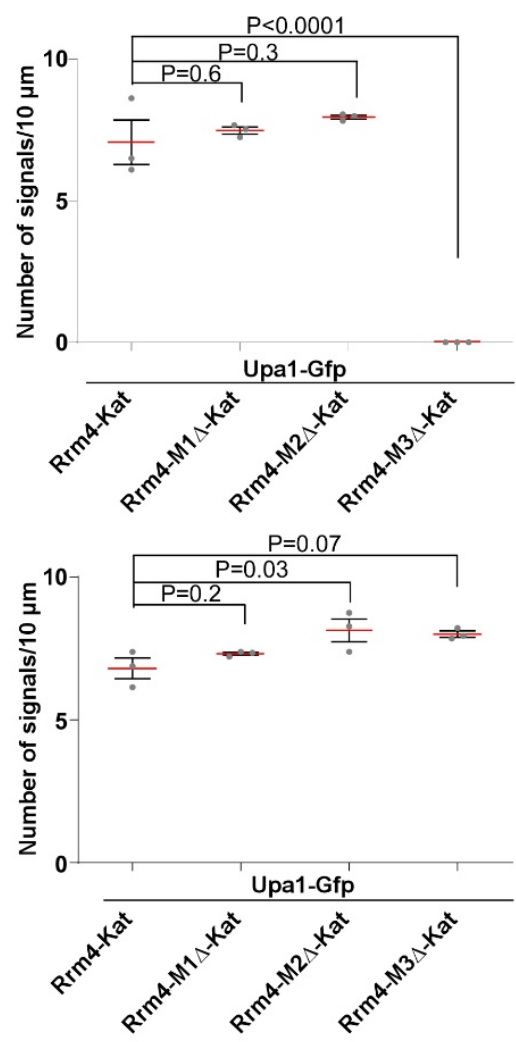

B
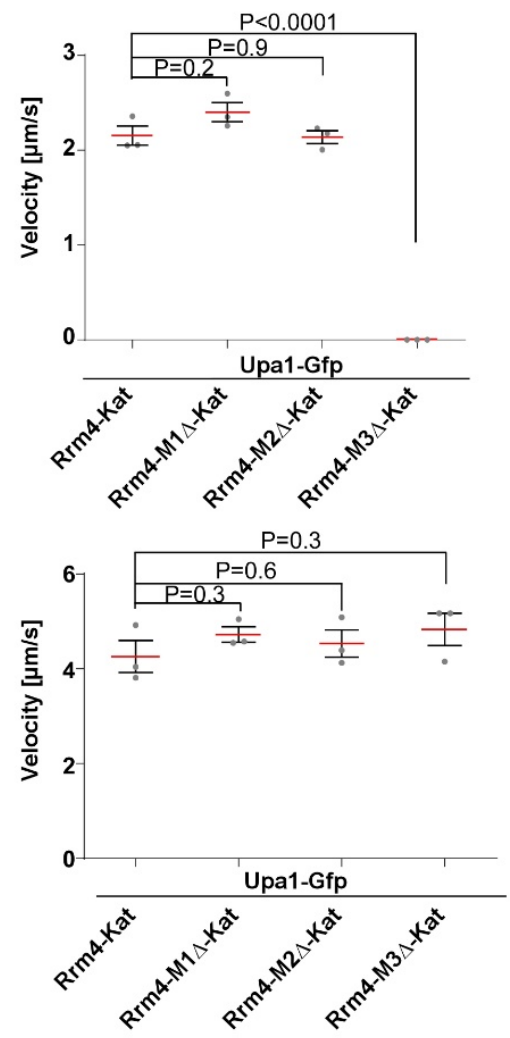

C
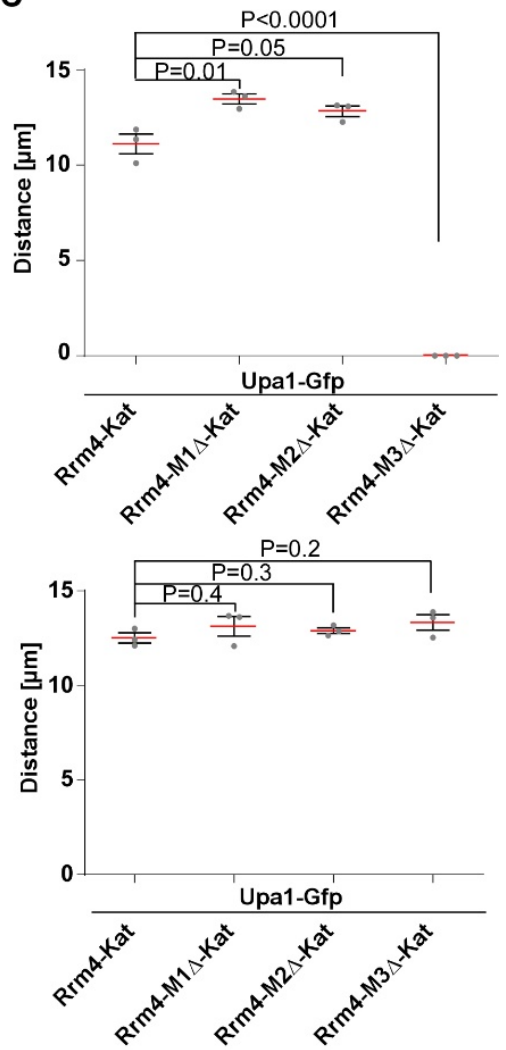

D

\begin{tabular}{|c|c|c|c|c|}
\hline upa1 & $r r m 4$ & Phenotype & $\begin{array}{c}\text { Endosomal } \\
\text { shuttling of } \\
\text { Rrm4 }\end{array}$ & $\begin{array}{l}\text { Microtuble } \\
\text { binding of } \\
\text { Rrm4 }\end{array}$ \\
\hline$w t$ & $w t$ & $w t$ & $w t$ & $w t$ \\
\hline$w t$ & $r r m 4 \Delta$ & bipolar & not applicable & not applicable \\
\hline$w t$ & $m 1 \Delta$ & $w t$ & $w t$ & $w t$ \\
\hline$w t$ & $m 2 \Delta$ & $w t$ & $w t$ & $w t$ \\
\hline$w t$ & $m 3 \Delta$ & bipolar & abolished & not applicable \\
\hline$w t$ & $w t$ & $w t$ & $w t$ & $w t$ \\
\hline$w t$ & $m 1,2 \Delta$ & $w t$ & $w t$ & $w t$ \\
\hline$p / 1,2 m$ & $w t$ & bipolar & aberrant & strong \\
\hline upa1s & $w t$ & bipolar & aberrant & strong \\
\hline$p / 1,2 m$ & $m 1,2 \Delta$ & bipolar & aberrant & strong \\
\hline $\mathrm{p} / 1 \mathrm{~m}$ & $w t$ & $w t$ & $w t$ & weak \\
\hline$p / 2 m$ & $w t$ & $w t$ & $w t$ & medium \\
\hline$p / 1 m$ & $m 1,2 \Delta$ & $w t$ & $w t$ & weak \\
\hline$p / 2 m$ & $m 1,2 \Delta$ & $w t$ & $w t$ & strong \\
\hline$p / 2 m$ & $m 1 \Delta$ & bipolar & $w t$ & medium \\
\hline$p / 2 m$ & $m 2 \Delta$ & bipolar & $w t$ & strong \\
\hline
\end{tabular}


Devan, Schott-Verdugo et al.

995 (A-C) Quantification of processive Rrm4-Kat (top) and Upa1-Gfp signals (bottom; (A)), 996 velocity of fluorescent Rrm4-Kat (top) and Upa1-Gfp signals (bottom; (B)) and the travelled 997 distance of processive Rrm4-Kat (top) and Upa1-Gfp signals (bottom; (C); per $10 \mu$ m of hyphal 998 length; only particles with a processive movement of $>5 \mu \mathrm{m}$ were conducted; data points 999 representing mean from $\mathrm{n}=3$ independent experiments, with mean of means, red line and SEM; 1000 unpaired two-tailed Student's t-test $(\alpha<0.05)$, for each experiment at least 25 hyphae were 1001 analysed per strain). (D) Summary of the in vivo analysis shown in Figure 4,5 and EV5A-C. 
bioRxiv preprint doi: https://doi. org/10.1101/2021 10.25.465676. this version posted October 25, 2021. The copyright holder for this preprint (which was not certified by peer review) is the author/funder, who has granted bioRxiv a license to display the preprint in perpetuity. It is made available under aCC-BY-NC 4.0 International license.

Devan, Schott-Verdugo et al.
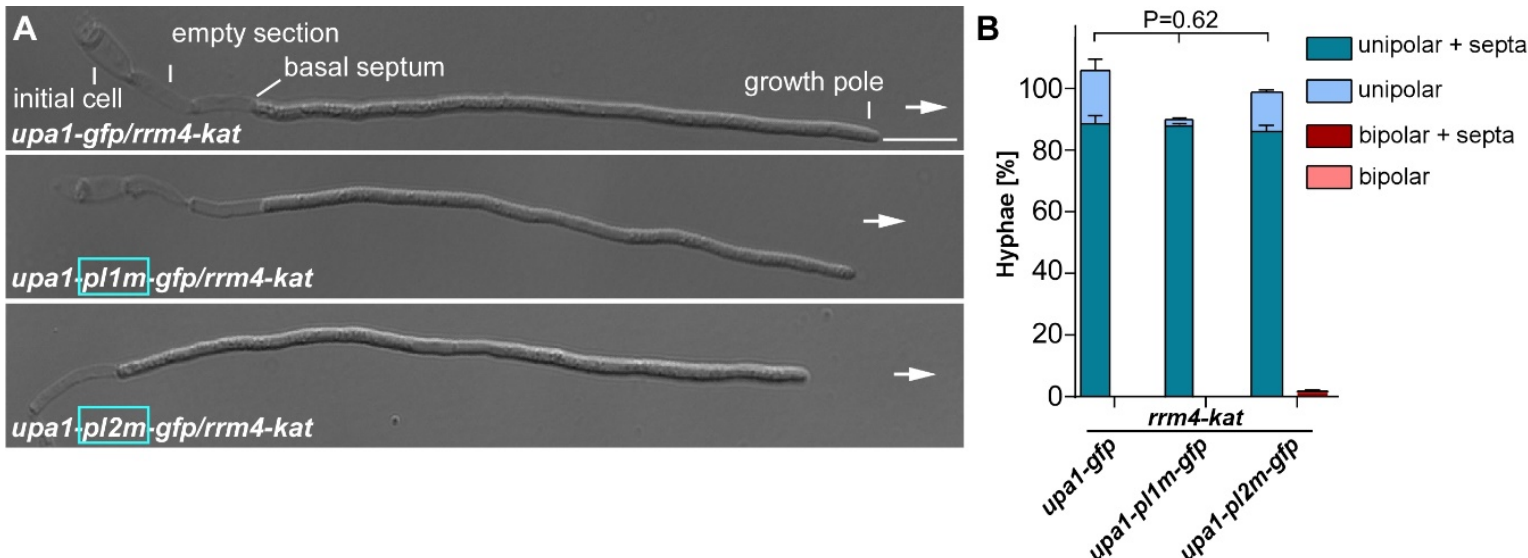

\section{C}
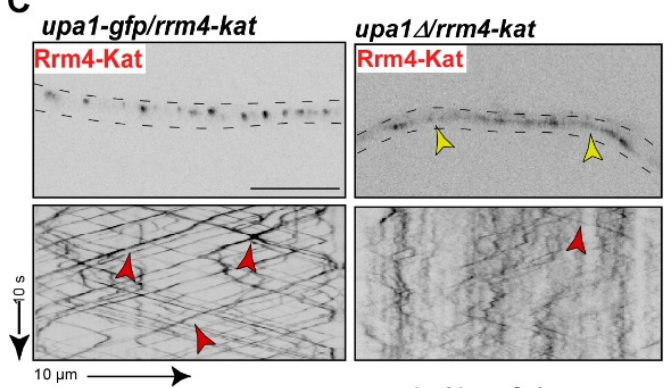

upa1-p/1,2m-gfp/

rrm4-m1,24-kat

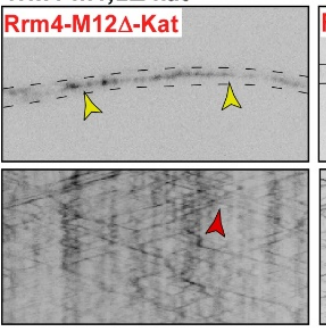

upa1-p/1m-gfp/rrm4-kat

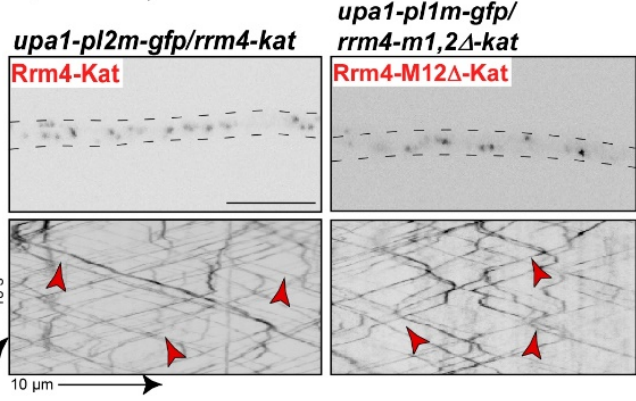

upa1-p/2m-gfp/

rrm4-m14-kat
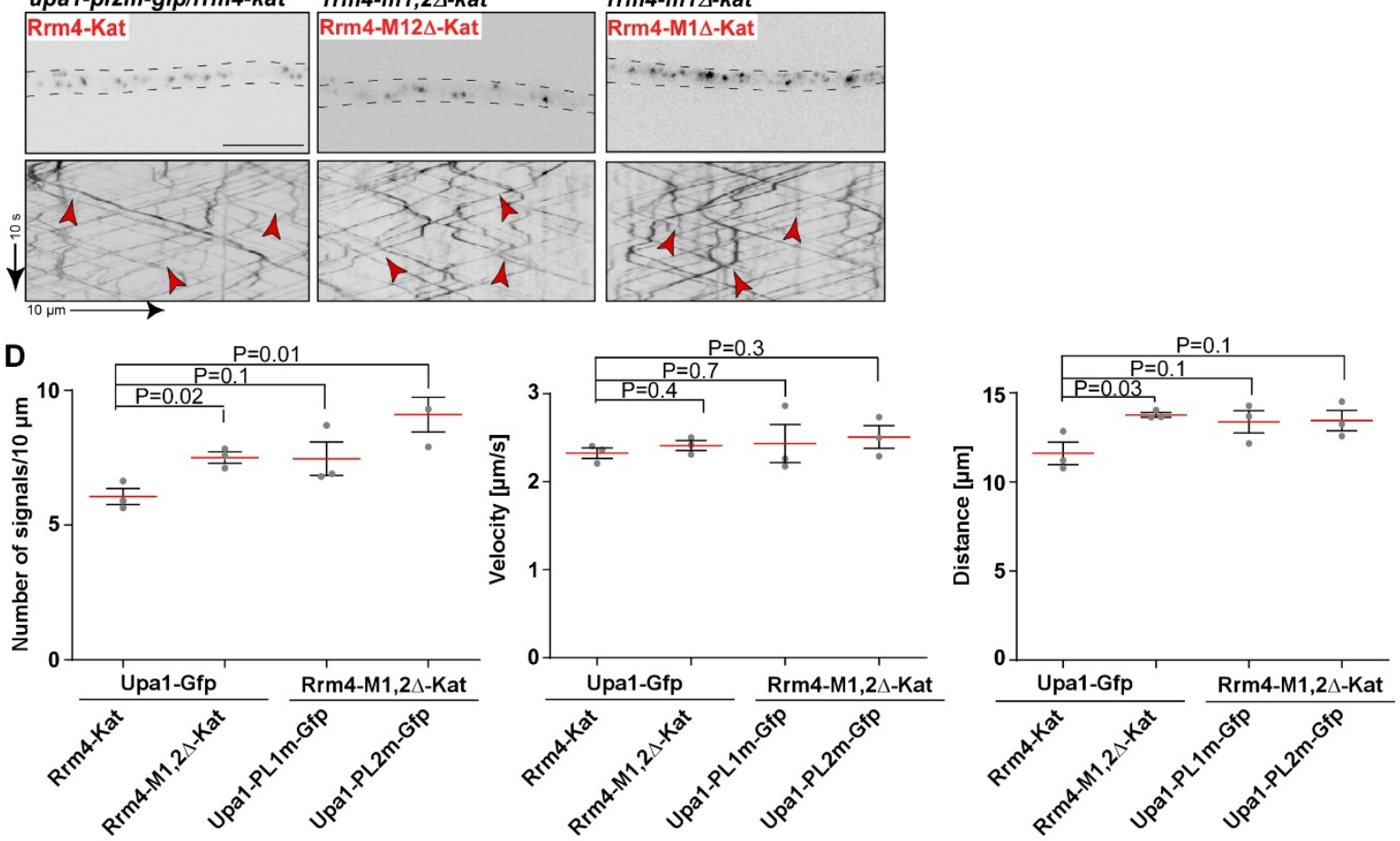

E
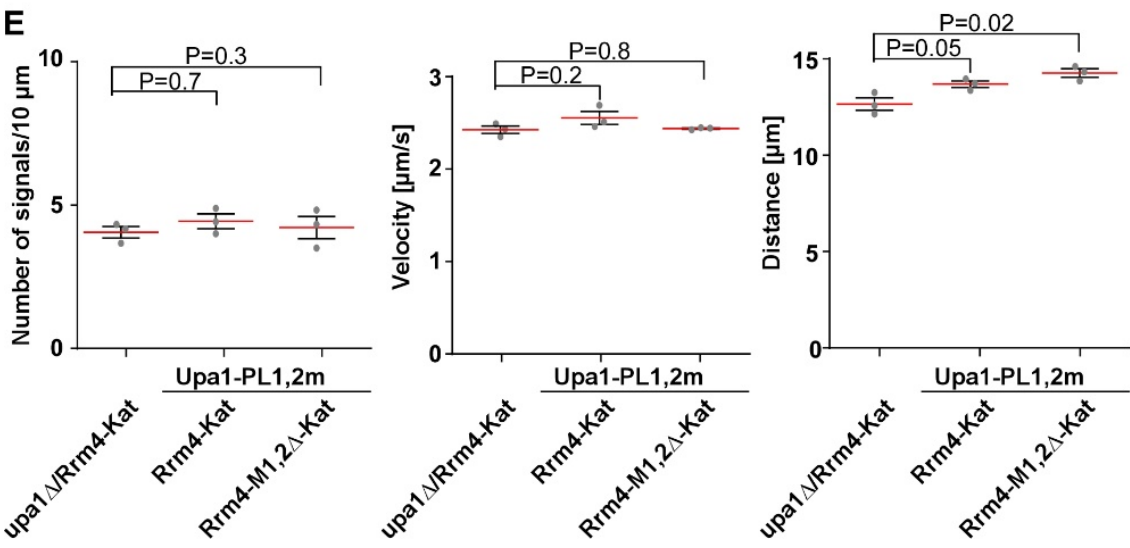
Devan, Schott-Verdugo et al.

Figure EV5. Deletion of MLLE1 ${ }^{\mathrm{Rrm} 4}$ and -2 cause defects in microtubule association.

1004 (A) Growth of AB33 derivatives in their hyphal form (6 h.p.i.; size bar $10 \mu \mathrm{m})$. Growth direction is marked by arrows. (B) Quantification of hyphal growth of AB33 derivatives shown in panel A (6 h.p.i.): unipolarity, bipolarity and basal septum formation were quantified (error bars, SEM.; $\mathrm{n}=3$ independent experiments, $>100$ hyphae were analysed per strain; For statistical evaluation, the percentage of uni- and bipolarity was investigated by using unpaired two-tailed Student's t-test $(\alpha<0.05)$.

(C) Micrograph and Kymograph of AB33 hyphae derivates (6 h.p.i.) expressing red and green fluorescent proteins as indicated. Fluorescence signals were detected simultaneously using dual-view technology (arrow length on the left and bottom indicates time and distance, respectively). Processive co-localising signals are marked by red arrowheads. Aberrant microtubule staining is indicated by a yellow arrowhead. (D-E) Quantification of processive Rrm4-Kat signals (left), velocity of fluorescent Rrm4-Kat (middle) and the travelled distance of processive Rrm4-Kat signals (right) related to figure $5 \mathrm{C}$ and EV5C, respectively ( per $10 \mu \mathrm{m}$ of hyphal length; only particles with a processive movement of $>5 \mu \mathrm{m}$ were conducted; data points representing mean from $\mathrm{n}=3$ independent experiments, with mean of means, red line and SEM; unpaired two-tailed Student's t-test $(\alpha<0.05)$, for each experiment at least 25 hyphae were analysed per strain). 